\title{
Orbital Exchange Calculations: An Alternative View of the Chemical Bond
}

\author{
Paul B. Merrithew ${ }^{\mathrm{a}}$ \\ PO Box 120, Amherst, New Hampshire 03031-0120 USA
}

\begin{abstract}
The purpose of this paper is to explore a model of the chemical bond which does not assume that the electrons of the chemical bonding electron pair can be unambiguously identified with either the left hand or right hand of the bonding atoms when their orbitals overlap to bond. In order to provide maximum flexibility in the selection of the electron's orbitals, the orbitals have been represented as spatial arrays and the calculations performed numerically. This model of the chemical bond assumes that the identifiability of the bonding electrons is a function of 1-(overlap/(1+overlap)) where the overlap of the two bonding electron's orbitals is calculated in the usual manner. The kinetic energy of the bonding electron pair and the energy required to meet the orthogonality requirements, mandated by the Pauli principle, are a function of overlap/(1+overlap). The model assumes that the bonding orbitals are straight-forward atomic orbitals or hybrids of these atomic orbitals. The results obtained by applying this simple approach to eleven di-atomics and seven common poly-atomics are quite good. The calculated bond lengths are generally within $0.005 \AA$ of the measured values and bond energies to within a few percent. Bond lengths for bonds to $\mathrm{H}$ are about $0.02 \AA$ high. Except for $\mathrm{H}_{2}$, bond lengths are determined, independent of bond energy, at that point where overlap/(1+overlap) equals 0.5 .
\end{abstract}

\section{INTRODUCTION}

The purpose of the work described here is to test a model for the chemical bond that assumes that the two electrons of the bonding pair are not completely identifiable, with respect to their source atom, when their orbitals overlap. Were the bonding electrons not identifiable in the overlap region it would be impossible to unambiguously identify every element of the orbital's distribution with either the atom on the right hand or the atom on the left side of the bond. Since the identification is ambiguous, nature would allow one to make the most energy favorable identification, which is to picture the electrons spread out over the whole bond when calculating the kinetic energy.

Distributions are representations of order (as differentiated from disorder or randomness). Narrow distributions represent high order, broader distributions less order. When two distributions overlap the order associated with the system decreases with their overlap because, in the overlap region, one can no longer identify each distribution element with a particular distribution. Overlap introduces randomness. Electron kinetic energy relates to order and electron distributions to representations of order.

In his early work ${ }^{1}$ applying LCAO-MO theory to $\mathrm{H}_{2}$, Coulson assumed that the two electrons of the bonding pair were identifiable. In subsequent applications of LCAO-MO theory to this molecule and more complex molecules, the same assumption has been made ${ }^{2}$. This assumption apparently has its origin in the view that a single electron can be uniquely assigned to one of two non-orthogonal overlapping spatial orbitals of different spin.

\footnotetext{
${ }^{\text {a }}$ Electronic mail: chembondsim@aol.com
} 
That the electrons of two overlapping orthogonal spatial orbitals of the same spin are not distinguishable is manifest in the so-called "exchange integral"3. The exchange integral evaluates the electron-electron repulsion in the overlap region. The total electron-electron repulsion is reduced by this quantity (Since an electron cannot repel itself.). Likewise, it is reasonable to hypothesize that the electrons of the bonding pair, which have non-orthogonal spatial orbitals of different spin, are also not distinguishable in the overlap region.

\section{A. Numerical Methods}

The calculations described herein are done numerically with the orbitals represented in huge identical spatial arrays of the form phi[i][j][k] where $\mathrm{i}$ is the index for the radius from the molecular axis, $\mathrm{j}$ represents the distance along the molecular axis and $\mathrm{k}$ is an array identifier. (Only two spatial coordinates are needed since the electron structure is axially symmetric or can be treated as such.) In a numerical calculation, integrals become summations. For example, the electron-electron repulsion becomes:

electron-electron repulsion $=$ constant

$\sum_{i=0}^{I M A X} \sum_{j=0}^{J M A X} \sum_{l=0}^{I M A X} \sum_{m=0}^{J M A X}$ phi[i][j][left array] phi[1][m][right array] ovr[ndist][i][1],

where

$\operatorname{ovr}[$ ndist $][\mathrm{i}][\mathrm{l}]$ is the reciprocal of distance between phi[i][j][left array] and phi[l][m] \{right array] and

ndist $=$ absolute value $(-\mathrm{j}+\mathrm{m})$.

The value of the constant depends on the dimensions associated with the array elements.

As a practical matter, for the repulsion calculation, adjacent phi[i][j] and phi[l][m] are consolidated to reduce the number of array elements. The electron-electron repulsion calculation requires less resolution than the kinetic energy calculation described below.

Numerical methods are advantageous because they do not presume a particular functional form for the orbitals. These numerical methods are particularly advantageous in making bonding orbitals which are orthogonal to the opposite core 1s electrons. Numerical methods permit the use of iterative analytical methods to find the lowest energy orbitals which meet the orthogonalization requirements.

\section{B. Kinetic Energy of Combined Orbital}

Kinetic energy $(\mathrm{KE})$ of an orbital is determined in the usual manner:

$$
\mathrm{KE}=\iint \phi \nabla^{2} \phi 2 \pi \mathrm{r} d r d l
$$

where $\phi$ represents a generic orbital and $\nabla^{2}$ is the Laplacian. The variable $r$ represents the radial distance from the bond axis and 1 represents the distance along the bond axis. Using numerical methods this becomes:

$$
\begin{aligned}
& \mathrm{KE}=\mathrm{constant} \sum_{i=0}^{I M A X} \sum_{j=1}^{J M A X} \\
& \quad((\operatorname{rrdn}[\mathrm{i}](\operatorname{phi}[\mathrm{i}-1][\mathrm{j}]-\operatorname{phi}[\mathrm{i}][\mathrm{j}])-\operatorname{rrup}[\mathrm{i}](\operatorname{phi}[\mathrm{i}][\mathrm{j}]-\operatorname{phi}[\mathrm{i}+1][\mathrm{j}]))) \operatorname{phi}[\mathrm{i}][\mathrm{j}]+ \\
& \quad \operatorname{constant} \sum_{i=0}^{I M A X} \sum_{j=1}^{J M A X} \\
& \quad((\operatorname{phi}[\mathrm{i}][\mathrm{j}+1]-\operatorname{phi}[\mathrm{i}][\mathrm{j}])-(\operatorname{phi}[\mathrm{i}][\mathrm{j}]-\operatorname{phi}[\mathrm{i}][\mathrm{j}-1]))(\operatorname{phi}[\mathrm{i}][\mathrm{j}] \operatorname{rr}[\mathrm{i}]),
\end{aligned}
$$
where

$\operatorname{rr}[\mathrm{i}]$ is the axial radius at $\mathrm{i}$ 
$\operatorname{rrdn}[\mathrm{i}]$ is one-half unit down the axial radius from $\operatorname{rr}[\mathrm{i}]$

$\operatorname{rrup}[\mathrm{i}]$ is one-half unit up the axial radius from $\operatorname{rr}[\mathrm{i}]$.

(In the equation above $\mathrm{i}=0$ leads to phi with a negative index (and therefore not determined).

This is of no consequence because its factor, $\operatorname{rrdn}[\mathrm{i}]=0$ when $\mathrm{i}=0$.)

The value of the constant depends on the dimensions associated with the array elements.

As a practical matter, to increase accuracy while not sacrificing processing speed, finer arrays have been created for areas close to the nucleus (where phi changes faster) and coarser arrays at a distance from the nucleus.

Another important quantity is the overlap of the bonding orbitals which is calculated in the usual manner:

$$
\text { overlap }=\iint \phi_{l} \phi_{r} 2 \pi \mathrm{r} d r d l,
$$

where $\phi_{l}$ represents the bonding atomic orbital on the left and $\phi_{r}$ the bonding atomic orbital on the right. The orbitals $\phi_{l}$ and $\phi_{r}$ are atomic orbitals which have been made orthogonal to the core electrons on the opposite atom. Overlap has a range from 0.0 to 1.0. The atomic orbitals which have been made orthogonal to the core electrons on the opposite atom have no net overlap with those core-electron orbitals:

$$
\begin{aligned}
& \iint \phi_{l} \phi_{1 \mathrm{sr}} 2 \pi \mathrm{r} d r d l=0.0 \text { and } \\
& \iint \phi_{r} \phi_{1 \mathrm{sl}} 2 \pi \mathrm{r} d r d l=0.0 .
\end{aligned}
$$

To calculate the kinetic energy when the identification of components of the orbitals as right versus left is ambiguous, one creates a hypothetical orbital, referred to as the combined orbital, $\phi_{l+r}$ which distributes the electron equally on the atoms left and right of the bond while preserving the electron density map of the original left and right atomic orbitals combined and meeting the orthogonality requirements.

For each spatial array element one computes:

phi[i][j][combined $]=$ square root

(phi[i][j][right_ortho] phi[i][j][right_ortho]+phi[i][j][left_ortho] phi[i][j][left_ortho]) .

When phi[i][j][left_ortho] and phi[i][j][right_ortho] are negative, a negative sign is given to the combined orbital. The array elements phi[i][j][left_ortho] and phi[i][j][right_ortho] are the array elements of atomic orbitals which have been altered to create orbitals which are orthogonal to the core electrons of the opposite atom $\left(\phi_{l}\right.$ and $\left.\phi_{r}\right)$. The analytic procedure used to convert the set of array elements, phi[i][j][left] and phi[i][j][right], the original atomic orbitals elements, designated as $\phi_{l}$ and $\phi_{r}$, to the set phi[i][j][left_ortho] and phi[i][j][right_ortho] is described in Section IIIA below.

Note that the combined orbital is not the sum of the right and left orbitals as this would change the electron density map by adding electron density between the atoms. The author knows of no explicit functions which describe the set phi[i][j][left_ortho] and phi[i][j][right_ortho] or $\phi_{l+r}$. These calculations can only be performed numerically.

The kinetic energy change associated with overlap of the atomic orbitals is designated $\mathrm{KE}_{\text {bond. }} \mathrm{KE}_{\text {bond }}$ is calculated:

$$
\begin{aligned}
& \mathrm{KE}_{\text {bond }}=(\text { overlap } /(1+\text { overlap })) \mathrm{KE}_{\text {net }} \\
& \text { where } \mathrm{KE}_{\text {net }}=\left(\mathrm{KE}_{\phi l+\mathrm{r}}-\mathrm{KE}_{\phi l}-\mathrm{KE}_{\phi r}\right)
\end{aligned}
$$


The total kinetic energy change for the bond is 2.0 times $\mathrm{KE}_{\text {bond. }}$ ( $\mathrm{KE}_{\text {bond }}$ is for one electron.) This approach to the kinetic energy assumes that, to the extent of overlap/(1+overlap), the electrons are spread over the bonding orbitals of both of the bonding atoms. To the extent of 1(overlap/(1+overlap)), the kinetic energy is that of the atomic orbitals which have been made orthogonal to the opposite core electrons (the set phi[i][j][left_ortho] and phi[i][j][right_ortho]).

\section{C. $\mathrm{H}_{2}$}

Applying this approach to find the kinetic energy of the $\mathrm{H}_{2}$ bonding electrons, I find a bond energy, $\mathrm{D}_{\mathrm{e}}$, of $4.06 \mathrm{eV}$ at a bond length of $0.753 \AA$ using an orbital scale factor (orbital reduction factor) of 1.15. (See column B of Table I for the results of this calculation at $0.754 \AA$.) The actual values are $D_{e}$ equal to 4.75 at a bond length of $0.741 \AA$. Some improvement can be made by polarizing the $\mathrm{H} 1 \mathrm{~s}$ orbitals by adding a small amount of $2 \mathrm{p}_{\mathrm{z}}(0.008)$ with a $2 \mathrm{pz}$ scale factor of 3.50 to the $\mathrm{H} 1 \mathrm{~s}$ orbital while retaining an orbital scale factor of 1.15. This results in a bond energy, $\mathrm{D}_{\mathrm{e}}$, of $4.67 \mathrm{eV}$ at a bond length of $0.754 \AA$. (See column $\mathrm{C}$ of Table I for the results of this calculation at $0.754 \AA$.) These are remarkably good results for such a simple approach, but since the $\mathrm{H}_{2}$ results could be fortuitous, the investigation needs to be extended to other molecules.

For purposes of comparison, Coulson's early MO calculations have been reproduced here. These results are shown in Table II. Coulson's MO approach gives poorer agreement with experiment, with $\mathrm{D}_{\mathrm{e}}$, of $3.49 \mathrm{eV}$.

Coulson gives a breakdown of similar calculations for $\mathrm{H}_{2}$ at 1.41 Bohr $(0.746 \AA)$ in his later book ${ }^{4}$. These are accurate to only about $0.1 \mathrm{eV}$. Coulson gives $17.8 \mathrm{eV}, 19.3 \mathrm{eV}, 27.2 \mathrm{eV}$ and $16.2 \mathrm{eV}$ for the electronic repulsion, nuclear repulsion, energy of two $\mathrm{H}$ atoms, and "energy of each separate molecular orbital", respectively. My similar calculations for the same quantities at 1.41 Bohr give $17.824 \mathrm{eV}, 19.299 \mathrm{eV}, 27.220 \mathrm{eV}$ and $16.095 \mathrm{eV}$.

Table I. Components of $\mathrm{H}_{2}$ calculations at $0.754 \AA$ (Energy in electron volts)

\begin{tabular}{|c|c|c|}
\hline A. Component & $\begin{array}{l}\text { B. Unpolarized 1s Orbital } \\
\text { orbital factor }=1.15\end{array}$ & $\begin{array}{l}\text { C. Polarized 1s Orbital } \\
\phi=f s_{b} 1 s+f p_{b} 2 p_{z} \\
f p_{b} f p_{b}=0.008 \\
2 p_{z} \text { orbital factor }=3.50 \\
1 s \text { orbital factor }=1.15\end{array}$ \\
\hline $\begin{array}{l}\text { Kinetic energy gain associated with sigma orbital } \\
\left.\text { overlap ( } 2 \mathrm{KE}_{\text {bond }}\right)\end{array}$ & 4.1416 & 4.1365 \\
\hline Nuclear-nuclear repulsion energy & -19.0957 & -19.0957 \\
\hline Nuclear to opposite bonding orbital energy & 34.3914 & 36.8282 \\
\hline Electron-electron repulsion energy & -14.7743 & -16.0927 \\
\hline Energy for $\mathrm{H}$ atom compression/polarization & -0.6056 & -1.1023 \\
\hline
\end{tabular}


Table II. Reproduction of Coulson's MO H2 calculation at 1.40 Bohr or 0.741 A (Energy in electron volts)

\begin{tabular}{lc}
\hline Component & $\begin{array}{c}\text { Contribution to } \\
\text { total energy }\end{array}$ \\
\hline Total kinetic energy of molecular orbitals & -30.8357 \\
Nuclear-nuclear repulsion energy & -19.4367 \\
Nuclear to molecular orbitals potential energy & 98.8386 \\
Electron-electron repulsion energy & -17.8501 \\
$\begin{array}{l}\text { Energy of two H atoms } \\
\text { orbital factor=1.197 }\end{array}$ & -27.2259 \\
\hline Total & 3.490 \\
\hline
\end{tabular}

Note: Actual energy minimum is at $0.731 \AA$

\section{ATOMIC ORBITALS AND ORBITAL SCALE FACTORS}

For the calculations described here, the atomic orbitals of Duncanson and Coulson ${ }^{5}$ have been used. The quantities Duncanson and Coulson call $\mu$ and $\mu c$ (These are equivalent to the effective nuclear charge [or orbital scale factor] for $2 \mathrm{~s}$ and $2 \mathrm{p}$ electrons.), are increased by factors (called fact herein) ranging from 1.0 to 1.055. Contracting an atomic orbital raises an atom's energy but enables a stronger bond. Table III gives the approximate energy impact of these small changes in the atomic parameters. The energy impact of these changes is usually less than $0.4 \mathrm{eV}$ and is spread among several bonds in a polyatomic molecule. The factors are usually not difficult to establish since the energy increases exponentially as the factor is increased. (The orbital scale factor for $\mathrm{C}+$ is taken as 1.10 and that for $\mathrm{O}$ - as 0.93 .)

Table II. Estimated Energy (eV) Associated with Orbital Scale Factor

\begin{tabular}{c|cccccc|} 
Atom & 1.01 & 1.02 & 1.03 & 1.04 & 1.05 & 1.055 \\
\hline B & - & 0.01 & 0.05 & 0.09 & 0.15 & \\
C & 0.01 & 0.04 & 0.11 & 0.20 & 0.33 & 0.44 \\
N & 0.03 & 0.11 & 0.22 & 0.41 & & \\
O & 0 & 0.10 & 0.27 & 0.54 & & \\
F & 0.04 & 0.20 & 0.50 & & & \\
\hline
\end{tabular}




\section{ORTHOGONALITY}

For calculations involving multi-electron atoms, orthogonality requirements must be considered. Consistent with the Pauli principle, the orbitals of electrons of the same spin must be orthogonal. When an atom presents a bonding orbital to the opposite atom two types of changes must be made to meet the orthogonality requirements: the bonding orbital must be made orthogonal to the "core" electrons on the opposite atom and the not-bonding electron orbitals must be changed/reconfigured to be orthogonal to the bonding orbital from the opposite atom.

\section{A. Core Orthogonality}

Herein, a bonding atomic orbital is made orthogonal to the opposite core by placing a node(s) in the orbital at the position of the nodes in the opposite bonding orbital. Since these calculations are performed analytically, using arrays to represent the orbitals, the orthogonalization is relatively easy. The goal is to find an orthogonal orbital with the same charge distribution (and potential energy) as the original atomic orbital. An orthogonal orbital with exactly the same charge density as the original atomic orbital is impossible because this would require a discontinuity in the function at the node. However, an iterative analytical procedure produces a satisfactory approximation of an orthogonal orbital, with approximately the same charge density as the original atomic orbital, but without a discontinuity.

An approximate, and normalized orbital is constructed from the atomic orbital which has a relatively gentle transition at the node. The approximation procedure does not permit a displacement of charge density from one side of the nucleus to another or cause a net displacement of charge toward, or away from, the nucleus. The bond energy is calculated for successively sharper node transitions. [Alternatively, just the difference $\mathrm{KE}_{\mathrm{bond}}-\left(\mathrm{KE}_{\phi}-\mathrm{KE}_{\phi}\right)$ could be calculated]. Usually, as the transition becomes sharper, the bond energy will improve slowly, and the overlap change little. At some point the bond energy will decrease. The orbital that has the best energy is utilized. Sometimes, usually when one or both of the bonding atoms are "soft" (H, light elements), the bond energy does not improve as the node transition becomes sharper. In these cases the bond energy decreases slowly as the node transition sharpens. At some point the bond energy will begin to deteriorate more quickly for a given change in the node transition. The function just prior to the inflection point is chosen. Although the selection of the orthogonal bonding orbital is sometimes not precise, the process does not appear to introduce an error of more than a few percent even in the worst cases.

There is a reason that the bond energy is relatively stable with changes in the bonding

orbital. As the node transition sharpens, $\mathrm{KE}_{\phi}$ increases. The increase in $\mathrm{KE}_{\phi}$ is accompanied by a corresponding increase in $\mathrm{KE}_{\phi 1+\mathrm{r}}$. The difference between these two quantities remains relatively constant.

Making the bonding atomic orbital orthogonal to the opposite core has the salubrious effect of making the two overlapping bonding orbitals positive where the other is positive, and negative where the other is negative. The combined orbital, $\phi_{l+r}$ has no discontinuities. 


\section{B. Valence Orthogonality}

When an atom presents a bonding orbital to the opposite atom, the opposite atom must change/reconfigure so that its orbitals, with the exception of its bonding orbital, are orthogonal to the bonding orbital. This is referred to here as valence electron orthogonalization. Consider atoms in di-atomic molecules. The atoms in di-atomic molecules typically have an $\mathrm{s}^{2} \mathrm{p}^{\mathrm{n}}$ configuration. To orthogonalize, the atoms reconfigure to $\mathrm{sp}_{z} \mathrm{p}_{\perp}^{\mathrm{n}-1} \mathrm{sp}_{\mathrm{o}}$ where $\mathrm{sp}_{\mathrm{o}}$ is an opposing hybrid orbital (taking $\mathrm{z}$ as the bond axis). The $2 \mathrm{~s}$ and $2 \mathrm{p}_{\mathrm{z}}$ orbitals of the atom hybridize to form an opposing orbital of the form $\mathrm{fs}_{\mathrm{o}} 2 \mathrm{~s}-\mathrm{fp}_{\mathrm{o}} 2 \mathrm{p}_{\mathrm{z}}$, (fso stands for fraction $\underline{\mathrm{s}}$ opposing) and a bonding orbital of the form $\mathrm{fs}_{\mathrm{b}} 2 \mathrm{~s}+\mathrm{fp}_{\mathrm{b}} 2 \mathrm{p}_{\mathrm{z}}\left(\mathrm{fs}_{\mathrm{b}}\right.$ stands for fraction $\underline{\mathrm{s}} \underline{\text { bonding }}$ ), where $\mathrm{fs}_{\mathrm{o}} \mathrm{fs}_{\mathrm{o}}+\mathrm{fp}_{\mathrm{o}} f \mathrm{p}_{\mathrm{o}}=1$. The coefficients $\mathrm{fs}_{\mathrm{o}}$ and $\mathrm{fp}_{\mathrm{o}}$ are chosen to make the opposing orbital orthogonal to the opposite bonding orbital. The opposing orbitals determine the bonding orbitals $\left(\mathrm{fs}_{\mathrm{b}}=\mathrm{fp}_{\mathrm{o}}\right.$ and $\mathrm{fp}_{\mathrm{b}}=\mathrm{fs}_{\mathrm{o}}$ ). In the case of a di-atomic, $\mathrm{fs}_{\mathrm{or}}$ (the subscripts $\mathrm{r}_{\mathrm{r}}$ and ${ }_{1}$ indicate right and left) and $\mathrm{fp}_{\mathrm{or}}$ and $\mathrm{fs}_{\mathrm{ol}}$ and $\mathrm{fp}_{\mathrm{ol}}$ are chosen to satisfy the simultaneous equations:

$$
\begin{aligned}
& \mathrm{fs}_{b 1} \mathrm{fs}_{\text {or }} \text { overlap } \mathrm{s} \_s \_n_{-}-\mathrm{fp}_{\mathrm{bl}} \mathrm{fp}_{\text {or }} \text { overlap } \mathrm{pz}_{-} \mathrm{pz} \_\mathrm{n}+
\end{aligned}
$$

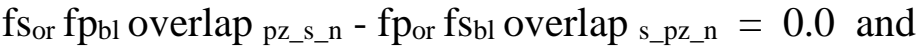

$$
\begin{aligned}
& \mathrm{fs}_{\mathrm{br}} \mathrm{fs}_{\mathrm{ol}} \text { overlap } \mathrm{s} \_s \_n_{-}-\mathrm{fp}_{\text {br }} \mathrm{fp}_{\mathrm{ol}} \text { overlap pz_pz_n }+ \\
& \mathrm{fs}_{\mathrm{al}} \mathrm{fp}_{\mathrm{br}} \text { overlap } \mathrm{pz} \_\mathrm{s} \_\mathrm{n}_{-}-\mathrm{fp}_{\mathrm{al}} \mathrm{fs}_{\mathrm{br}} \text { overlap } \mathrm{s}_{-} \mathrm{pz} \_\mathrm{n}=0.0 \text {. }
\end{aligned}
$$

The overlap $s_{-} s_{-} n$ is the overlap of the $2 \mathrm{~s}$ atomic orbitals (not core orthogonalized) and etc.

\section{Orthogonality Energy}

The orthogonalizations described above in Section IIIA need only be taken to the extent that the bonding atomic orbitals are identifiable (when the orbitals are identifiable the bond is said to be "not bonding"). The measure of identifiability (bond is "bonding") is termed fraction_bonding and is calculated:

$$
\text { fraction_bonding = overlap/(1.0+overlap). }
$$

The energy required to core orthogonalize a bonding orbital, $\mathrm{KE}_{\text {core_ortho, }}$ is:

$$
\mathrm{KE}_{\text {core_ortho }}=(1.0 \text {-fraction_bonding })\left(\mathrm{KE}_{\phi}-\mathrm{KE}_{\phi}\right)
$$

where $\mathrm{KE}_{\phi}$ is the kinetic energy of the core orthogonalized atomic orbital and $\mathrm{KE}_{\phi}$ is the kinetic energy of the original atomic orbital.

For two hybrid sigma bonding orbitals (comprised of the $2 \mathrm{~s}$ and $2 \mathrm{p}_{\mathrm{z}}$ atomic orbitals) of the form $\phi_{\mathrm{r}}=\mathrm{fs}_{\mathrm{br}} 2 \mathrm{~s}+\mathrm{fp}_{\mathrm{br}} 2 \mathrm{p}_{\mathrm{z}}$ and $\phi_{\mathrm{l}}=\mathrm{fs}_{\mathrm{bl}} 2 \mathrm{~s}+\mathrm{fp}_{\mathrm{bl}} 2 \mathrm{p}_{\mathrm{z}}$, the energy to core orthogonalize the hybrid orbitals, $\mathrm{KE}_{\text {core_ortho, is: }}$

$$
\begin{aligned}
& \mathrm{KE}_{\text {core_ortho }}=(1 \text {-fraction_bonding }) \\
& \left(\left(\mathrm{fs}_{\mathrm{bl}} \mathrm{fs}_{\mathrm{br}} \mathrm{fs}_{\mathrm{bl}} \mathrm{fs}_{\mathrm{br}}\left(\mathrm{KE}_{\mathrm{s}_{-} \mathrm{sal}}-\mathrm{KE}_{\mathrm{sl}}\right)+\mathrm{fs}_{\mathrm{bl}} \mathrm{fs}_{\mathrm{br}} \mathrm{fs}_{\mathrm{bl}} \mathrm{fs}_{\mathrm{br}}\left(\mathrm{KE}_{\mathrm{s}_{-} \mathrm{sar}}-\mathrm{KE}_{\mathrm{sr}}\right)+\right.\right.
\end{aligned}
$$

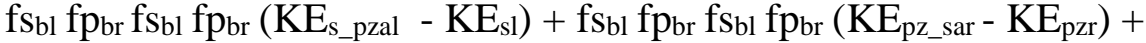

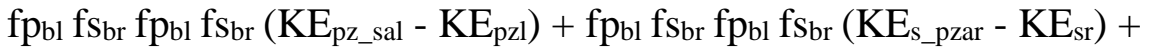




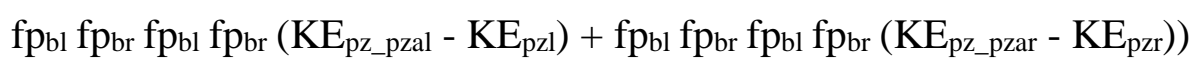

where $\mathrm{KE}_{\mathrm{sl}}$ and $\mathrm{KE}_{\mathrm{pzl}}$ are the kinetic energies of the left $2 \mathrm{~s}$ and $2 \mathrm{p}_{\mathrm{z}}$ initial atomic orbitals and, $\mathrm{KE}_{\text {sr }}$ and $\mathrm{KE}_{\mathrm{pzr}}$ are those on the right. $\mathrm{KE}_{\mathrm{s}_{-} \text {sal }}$ is the kinetic energy of the $\mathrm{s}$ orbital on the left which has been orthogonalized with the right hand $\mathrm{s}$ (the subscript "a" indicates the orthogonalized orbital). $\mathrm{KE}_{\text {s_pzal }}$ is the kinetic energy of the s orbital on the left which has been orthogonalized with the right hand $2 \mathrm{p}_{\mathrm{z}}$. $\mathrm{KE}_{\mathrm{pz} \_ \text {sal }}$ is kinetic energy of the $2 \mathrm{p}_{\mathrm{z}}$ orbital on the left which has been orthogonalized with the right hand $s . \mathrm{KE}_{\mathrm{pz} \_ \text {pzal }}$ is kinetic energy of the $2 \mathrm{p}_{\mathrm{z}}$ orbital on the left which has been orthogonalized with the right hand $\mathrm{p}_{\mathrm{z}}$. The suffix ${ }_{r}$ indicates the corresponding orbitals on the right.

In the potential energy calculations, the reconfiguration required to meet the valence orthogonalization requirement need only to be taken to the extent of (1.0-fraction_bonding). If a $2 \mathrm{~s}$ orbital is reconfigured to a fs $2 \mathrm{~s}_{\mathrm{o}} \mathrm{fp}_{\mathrm{o}} 2 \mathrm{p}_{\mathrm{z}}$ hybrid to become orthogonal, then, in the potential energy calculations, the electron is considered to be in an $2 \mathrm{~s}$ orbital for fraction_bonding and in a $\mathrm{fs}_{\mathrm{o}} 2 \mathrm{~s}-\mathrm{f} \mathrm{p}_{\mathrm{o}} 2 \mathrm{p}_{\mathrm{z}}$ hybrid orbital for (1.0-fraction_bonding). In this latter case, the bond energy is also adjusted for the energy required to promote the $s$ to $p$. If the energy to promote an $s$ to $p$ is given by stop, then the bond energy is decreased by $\mathrm{stop} \mathrm{fp}_{\mathrm{o}} \mathrm{fp}_{\mathrm{o}}$ (1.0-fraction_bonding).

A table of the energies required for the $2 \mathrm{~s}$ to $2 \mathrm{p}$ promotion for the first row atoms has been developed for this work. The stop values are in the order $\mathrm{B} \leq \mathrm{C}<\mathrm{N} \leq \mathrm{O} \leq \mathrm{F}$, positive atom $\leq$ neutral atom $\leq$ negative atom, high symmetry $\leq$ low symmetry and unpaired $\leq$ paired. The stop values used in this work are presented in Table IV. While stop values could be calculated for each bond, a table-driven approach has been utilized because it results in shorter computation times and does not appear to degrade accuracy. The stop values have been applied consistently

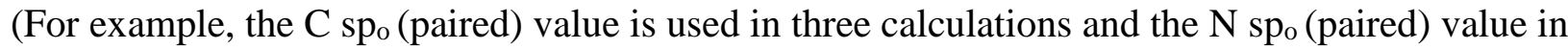
four.). Since fraction_bonding is typically 0.5 and $\mathrm{fp}_{\mathrm{o}} \mathrm{fp}_{\mathrm{o}} \sim 0.5$, the energy charged to a bond for $2 \mathrm{~s}$ to $2 \mathrm{p}$ promotion is typically less than or equal to half the stop value.

Table IV. Estimated Energy to Promote 2s to 2p (stop) Values

\begin{tabular}{c|cc|} 
Species & $2 \mathrm{p}$ Orbital Type & stop Energy/eV \\
\hline $\mathrm{B}$ & $\mathrm{sp}_{\mathrm{o}}$ (unpaired) & 4.35 \\
$\mathrm{~B}$ & $\mathrm{sp}_{\mathrm{o}}$ (paired) & 6.55 \\
$\mathrm{C}+$ & $\mathrm{sp}_{\mathrm{o}}$ (unpaired) & 4.35 \\
$\mathrm{C}+$ & $\mathrm{p}_{\pi}$ & 5.05 \\
$\mathrm{C}$ & $\mathrm{T}_{\mathrm{d}}$ & 6.55 \\
$\mathrm{C}$ & $\mathrm{sp}_{\mathrm{o}}$ (unpaired) & 6.55 \\
$\mathrm{C}$ & $\mathrm{p}_{\perp}$ (unbonded) & 6.95 \\
$\mathrm{C}$ & $\mathrm{p}_{\pi}$ & 7.50 \\
$\mathrm{C}$ & $\mathrm{sp}_{\mathrm{o}}($ paired,bonding) & 7.90 \\
$\mathrm{~N}$ & $\mathrm{sp}_{\mathrm{o}}$ (paired) & 12.40 \\
$\mathrm{O}$ & $\mathrm{sp}_{\mathrm{o}}$ (paired) & 16.60 \\
$\mathrm{O}-$ & $\mathrm{sp}_{\mathrm{o}}$ (paired) & 16.60 \\
\hline
\end{tabular}




\section{Core Orthogonality of a Second Sigma Pair}

Most atoms in di-atomic molecules and some atoms in other molecules have more than one bond pair of electrons with sigma symmetry. For example consider $\mathrm{N}_{2}$. $\mathrm{N}$ has the configuration $1 s^{2} 2 s^{2} 2 p^{3}$ or $1 s^{2} 2 s^{2} 2 p_{\perp}^{2} 2 p_{z}$. There are two possibilities for sigma bonds: an $\mathrm{sp}$ hybrid to sp hybrid bond and an s to s bond. To the extent that one pair (or both pairs) of the bonding electrons are not identifiable, (fraction_bonding), the second 2 s electron remains in place. To the extent that this s to s bond pair is not bonding (1-fraction_bonding second_set $_{\text {, }}$, the second $2 \mathrm{~s}$ must also be made orthogonal to the opposite core electrons. The energy to core orthogonalize a second sigma orbital $\mathrm{KE}_{\text {core_ortho_x, }}$ is, in general, for the left:

$$
\begin{aligned}
& \mathrm{KE}_{\text {core_ortho_xl }}=\text { fraction_bonding }(1.0 \text {-fraction_bonding } \text { second_set }) \\
& \left(\mathrm{fs}_{\mathrm{bl}} \mathrm{fs}_{\mathrm{br}} \mathrm{fs}_{\mathrm{bl}} \mathrm{fs_{ \textrm {br } }}\left(\mathrm{KE}_{\mathrm{s}_{-} \mathrm{sal}}-\mathrm{KE}_{\mathrm{sl}}\right)+\right. \\
& f_{b b l} f_{b r} f s_{b l} f p_{b r}\left(K_{S_{s} p z a l}-K_{E_{s l}}\right)+ \\
& \mathrm{fp}_{\mathrm{bl}} \mathrm{fs}_{\mathrm{br}} \mathrm{fp}_{\mathrm{bl}} \mathrm{fs}_{\mathrm{br}}\left(\mathrm{KE}_{\mathrm{pz} \_\mathrm{sal}}-\mathrm{KE}_{\mathrm{pzl}}\right)+
\end{aligned}
$$

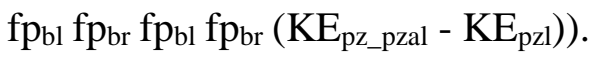

The calculations for the right side are analogous to those on the left.

As (12) indicates the $\mathrm{KE}_{\text {core_ortho_x }}$ penalty is taken only to the extent of overall

fraction_bonding. If there are second sigma bonding orbitals on both sides of the bond and these bond, then the $\mathrm{KE}_{\text {core_ortho_x }}$ penalty is further reduced to the extent that the second set of sigma orbitals themselves bond, fraction_bonding second_set. $_{\text {_ }}$

\section{SIGMA HYBRID ORBITAL OVERLAP AND KINETIC ENERGY}

For a single set of hybrid sigma bonding orbitals of the form $\phi_{\mathrm{r}}=\mathrm{fs} \mathrm{br}_{\mathrm{r}} 2 \mathrm{~s}+\mathrm{f} \mathrm{p}_{\mathrm{br}} 2 \mathrm{p}_{\mathrm{z}}$ and $\phi_{\mathrm{l}}=$ $\mathrm{fs}_{\mathrm{brl}} 2 \mathrm{~s}+\mathrm{fp}_{\mathrm{bl}} 2 \mathrm{p}_{\mathrm{z}}$, the quantities overlap and $\mathrm{KE}_{\text {bond }}$ are:

$$
\begin{aligned}
& \text { overlap }=\mathrm{fs}_{\mathrm{bl}} \mathrm{fs}_{\mathrm{br}} \text { overlap } \mathrm{s} \text {-s }+\mathrm{fp}_{\mathrm{bl}} \mathrm{fp}_{\mathrm{br}} \text { overlap } \mathrm{pz-pz}+ \\
& f_{b l} f_{b r} \text { overlap pz-s }+f_{b l} f_{b r} \text { overlap s-pz and } \\
& \mathrm{KE}_{\text {bond }}=(1.0 /(1.0+\text { overlap }))\left(\mathrm{fs}_{\mathrm{bl}} \mathrm{fs}_{\mathrm{br}} \text { overlap }_{\mathrm{s}-\mathrm{s}} \mathrm{KE}_{\text {net s-s }}+\right. \\
& f_{p b} f_{b r} \text { overlap pz-pz } K E_{\text {net } p z-p z}+f_{b l} f_{b r} \text { overlap pz-s } K E_{\text {net pz-s }}+ \\
& \mathrm{fs}_{\mathrm{bl}} \mathrm{fp}_{\mathrm{br}} \text { overlap s-pz } \mathrm{KE} \text { net s-pz). }
\end{aligned}
$$

Obviously, overlap cannot exceed 1.0, nor can fraction_bonding exceed 0.5. Except for the bonds of some "soft" atoms (H typically) fraction_bonding generally reaches the limit of 0.5. The limitation on overlap makes it possible, in most cases, to determine bond lengths without a complete treatment of bond energy. With a few exceptions, bond energy increases as the bond length decreases until fraction_bonding $=0.5$ is reached.

\section{DUAL AND PARALLEL BONDS}

As mentioned above, most atoms in di-atomic molecules and some atoms in other molecules have more than single pair of electrons that have the appropriate symmetry for sigma 
bonding. Both of these pairs bond. This results in what is described herein as dual bonding or parallel bonding. Dual/parallel bonds are not double bonds in the traditional sense, i.e a sigma bond and a pi bond. Dual/parallel bonds entail two sigma bonds. Parallel bonding differs from dual bonding in that the second set of bonding orbitals does not reconfigure when the bond is not bonding. Dual bonding is far more common than parallel bonding. Parallel bonding is exhibited in $\mathrm{F}_{2}, \mathrm{He}_{2}{ }^{+}$and partially in other compounds.

\section{A. Dual Bonding}

The calculation of dual overlap, fraction_bonding and $\mathrm{KE}_{\text {bond }}$ differs somewhat from that of the single sigma bond because simultaneous overlaps must be taken in account.

Consider two atoms each with a sigma bonding configuration of $2 s^{2} 2 p_{z}\left(\right.$ e.g. $\left.\mathrm{N}_{2}\right)$. The dual bond between these atoms could be considered as an sp-sp hybrid bond and an s-s bond with each weighted by 0.5 . Alternatively, the dual bond between these atoms could be considered as an sp-sp hybrid bond, an s-s bond, an sp-s bond and an s-sp bond with each weighted by 0.25 . In the latter case $\left(\mathrm{s}^{2} \mathrm{p}_{\mathrm{z}}\right.$ on both sides), the relevant quantities are:

$$
\begin{aligned}
& \text { fraction_bonding }{ }_{\mathrm{s}-\mathrm{s}}=\text { overlap }_{\mathrm{s}_{-} \mathrm{s}}\left(1.0+\text { overlap }_{\mathrm{s}_{-} \mathrm{s}}\right) \\
& \text { fraction_bonding }_{\mathrm{s} \text {-sp }}=\text { overlap }_{\mathrm{s} \_\mathrm{sp}} /\left(1.0+\text { overlap }_{\mathrm{s} \_\mathrm{sp}}\right) \\
& \text { fraction_bonding } \text { sp-s }_{-}=\text {overlap }_{\text {sp_s }} /\left(1.0+\text { overlap } \text { sp_s }_{\text {s }}\right) \\
& \text { fraction_bonding } \text { sp-sp }_{-}=\text {overlap }_{\text {sp_sp }} /(1.0+\text { overlap sp_sp }) \\
& \text { fraction_bonding ave }=0.25 \text { (fraction_bonding }{ }_{s-s}+\text { fraction_bonding }{ }_{s-s p}+ \\
& \text { fraction_bonding sp-s }+ \text { fraction_bonding sp-sp) } \\
& \text { overlap } \left._{\text {ave }}=\text { fraction_bonding ave/(1.0-fraction_bonding ave }\right) \\
& \text { simultaneous_bond }{ }_{\text {s-s/sp-sp }}=\text { fraction_bonding } \text { s-s }_{\text {f }} \text { fraction_bonding sp-sp } \\
& \text { simultaneous_bond } \mathrm{s-sp/sp-s}=\text { fraction_bonding }{ }_{\mathrm{s}-\mathrm{sp}} \text { fraction_bonding } \mathrm{sp-s} \\
& \text { overlap }_{\text {s-s/sp-sp }}=\text { simultaneous_bond }{ }_{\text {s-s/sp-sp }} /\left(1.0-\text { simultaneous_bond }{ }_{\text {s-s/sp-sp }}\right)
\end{aligned}
$$

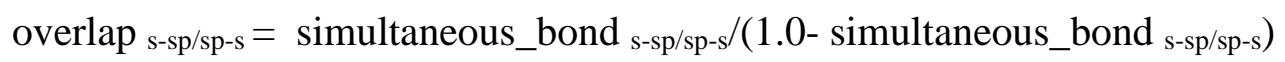

$$
\begin{aligned}
& \text { overlap }=2 \text { overlap }_{\text {ave }}-\text { overlap }_{\text {sp-s/s-sp }}-\text { overlap }_{\text {s-sp/sp-s }} \\
& \text { fraction_bonding }=\text { overlap/ (1.0+overlap) } \\
& \text { factor }=\text { fraction_bonding/fraction_bonding ave } \\
& \mathrm{KE}_{\text {bond }}= \\
& \text { factor } 0.25\left(\mathrm{KE}_{\text {bond s-s }}+\mathrm{KE}_{\text {bond s-sp }}+\mathrm{KE}_{\text {bond sp-s }}+\mathrm{KE}_{\text {bond sp-sp }}\right)
\end{aligned}
$$


With the $\mathrm{N}_{2}$ bonding configurations, both sides $2 \mathrm{~s}^{2} 2 \mathrm{p}_{\mathrm{z}}$, the dual bond overlap is actually somewhat less than the overlap of the sp-sp overlap alone. This is because the s-s overlap is much less than the sp-sp overlap.

Consider two atoms each with a sigma bonding configuration of $2 \mathrm{~s}^{2} 2 \mathrm{p}_{\mathrm{z}}^{2}$ (e.g. $\left.\mathrm{O}_{2}\right)$. In this case the relevant quantities are:

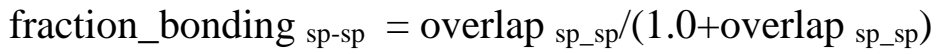

$$
\begin{aligned}
& \text { fraction_bonding ave = fraction_bonding sp-sp }
\end{aligned}
$$

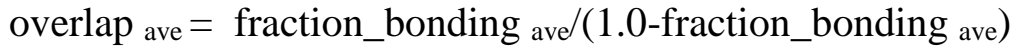

$$
\begin{aligned}
& \text { simultaneous_bond sp-sp/sp-sp = fraction_bonding sp-sp fraction_bonding sp-sp } \\
& \text { overlap }_{\text {sp-sp/sp-sp }}=\text { simultaneous_bond sp-sp/sp-sp } /(1.0 \text { - simultaneous_bond sp-sp/sp-sp }) \\
& \text { overlap }=2 \text { overlap }_{\text {ave }}-2 \text { overlap }_{\text {sp-sp/sp-sp }} \\
& \text { fraction_bonding = overlap/ (1.0+overlap) } \\
& \text { factor }=\text { fraction_bonding/fraction_bonding ave } \\
& \mathrm{KE}_{\text {bond }}=\text { factor } \mathrm{KE}_{\text {bond sp-sp }}
\end{aligned}
$$

With these bonding configurations, both atoms $2 \mathrm{~s}^{2} 2 \mathrm{p}_{\mathrm{z}}{ }^{2}$, the dual bond overlap is somewhat more than the overlap of the sp-sp overlap alone.

Consider two atoms, one with a sigma bonding configuration of $2 s^{2} 2 p_{z}$ and one with a sigma bonding configuration of $2 \mathrm{~s}^{2} 2 \mathrm{p}_{\mathrm{z}}{ }^{2}$ (e.g. NO). In this case the relevant quantities are:

$$
\begin{aligned}
& \text { fraction_bonding }{ }_{\mathrm{s}-\mathrm{sp}}=\text { overlap }_{\mathrm{s} \_\mathrm{sp}} /\left(1.0+\text { overlap }_{\mathrm{s} \_\mathrm{sp}}\right) \\
& \text { fraction_bonding }_{\mathrm{sp}-\mathrm{sp}}=\text { overlap }_{\mathrm{sp} \_\mathrm{sp}} /\left(1.0+\text { overlap }_{\mathrm{sp} \_s p}\right) \\
& \text { fraction_bonding ave }=0.5 \text { (fraction_bonding s-sp }+ \text { fraction_bonding sp-sp) } \\
& \text { overlap } \left._{\text {ave }}=\text { fraction_bonding ave/(1.0-fraction_bonding ave }\right) \\
& \text { simultaneous_bond s-sp/sp-sp=fraction_bonding s-sp fraction_bonding sp-sp } \\
& \text { overlap }_{\mathrm{s} \text {-sp/sp-sp }}=\text { simultaneous_bond }_{\mathrm{s} \text {-sp/sp-sp }} /(1.0 \text { - simultaneous_bond } \mathrm{s-sp} / \mathrm{sp} \text {-sp })
\end{aligned}
$$

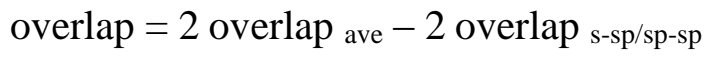

$$
\begin{aligned}
& \text { fraction_bonding }=\text { overlap/ }(1.0+\text { overlap }) \\
& \text { factor }=\text { fraction_bonding/fraction_bonding ave } \\
& \mathrm{KE}_{\text {bond }}=\text { factor } 0.5\left(\mathrm{KE}_{\text {bond s-sp }}+\mathrm{KE}_{\text {bond sp-sp }}\right)
\end{aligned}
$$

\section{B. Parallel Bonding}


Parallel bonding is a type of dual bonding that occurs when, instead of reconfiguring to orthogonalize, a second sigma orbital remains in place and forms a node to make it orthogonal to the opposite side bonding orbital. The best example of parallel bonding is $\mathrm{F}_{2}$. $\mathrm{F}$ has a bonding configuration of $1 s^{2} 2 s^{2} 2 p_{z}^{2} 2 p_{x y}{ }^{3}$. For parallel bonding, fraction_bonding is simply the sum of fraction_bonding for each of the two sigma bonds. So for the $\mathrm{F}_{2}$ parallel bond:

$$
\begin{aligned}
& \text { fraction_bonding }=\text { fraction_bonding sp-sp }+ \text { fraction_bonding sp-sp and } \\
& \mathrm{KE}_{\text {bond }}=\mathrm{KE}_{\text {bond sp-sp }}+\mathrm{KE}_{\text {bond sp-sp }} \text {. }
\end{aligned}
$$

Since fraction_bonding calculated in this manner is subject to the usual constraint (fraction_bonding $\leq 0.5$ ) parallel bonding results in relatively long bond lengths and is usually associated with molecules which require $\mathrm{p}_{\pi}$ orthogonalization (e.g. $\mathrm{F}_{2}$ )(See Section VI.C below).

\section{PI BONDING, PI RESONANCE AND PI ORTHOGONALIZATION}

\section{A. Pi Bonding}

The kinetic energy reduction associated with pi bonding, analogous to that of sigma bonding, is:

$$
\begin{aligned}
& \mathrm{KE}_{\text {bond } \_}=\text {fraction_bonding }_{\pi}\left(\mathrm{KE}_{\text {combined_}} \pi-\mathrm{KE}_{\pi \_1}-\mathrm{KE}_{\pi_{-} \mathrm{r}}\right) \\
& \text { where } \\
& \text { fraction_bonding } \pi=\operatorname{overlap}_{\pi} /\left(1.0+\operatorname{overlap}_{\pi}\right) .
\end{aligned}
$$

Pi overlaps are much smaller than sigma overlaps, usually in the range of 0.1 to 0.3 . Pi bonding only occurs to the extent that both pi bonding orbitals have the appropriate symmetry.

\section{B. Pi Resonance}

When the bonding electron is free to move from the right bonding orbital to the left, or from the left to the right, fraction_bonding in (39) above is 0.5 . The kinetic energy reduction associated with full pi resonance, $\mathrm{KE}_{\mathrm{bond} \_} \pi_{-}$res, is:

$$
\mathrm{KE}_{\text {bond_} \_\_ \text {res }}=0.5\left(\mathrm{KE}_{\text {combined_ } \pi}-\mathrm{KE}_{\pi \_1}-\mathrm{KE}_{\pi_{-} \mathrm{r}}\right)
$$

For these calculations, the energy associated with the formation of a positively charge species in a resonance is obtained from tables of ionization potentials ${ }^{6}$. The energy associated with the formation of negatively charged species is obtained from tables of electron affinities ${ }^{7}$.

\section{Pi Orthogonalization}

When the $\mathrm{p}_{\pi}$ orbitals on the atom on one side of the bond are more than half full (three or four electrons) and the $\mathrm{p}_{\pi}$ orbitals on the other side are at least half full, then, one of each of the spin paired pi orbitals must be made orthogonal to the pi bonding orbitals from the opposite side. This orthogonalization is analogous to that described in Section IIIA above with respect to sigma bonding, with a node placed in the $\mathrm{p}_{\pi}$ orbital to make it orthogonal to the opposite pi bonding orbital. An analytical procedure, similar to the one used for core orthogonalization described 
above, is used to find the optimal node position and node transition. As in core orthogonalization, this procedure attempts to maintain the atomic orbital density distribution as closely as possible. Analogous to sigma bonding, the pi orthogonalization penalty is taken only to the extent of (1.0-fraction_bonding $\left.{ }_{\pi}\right)$.

\section{SECONDARY BONDING}

In poly-atomic molecules, bonding occurs not only to the closest atom, but also to all atoms in the molecule with which it significantly overlaps. Secondary/tertiary bonding differs from primary bonding in three ways. First, the bond axis of the primary is retained in the secondary, tertiary, etc.. Secondly, secondary bonding is reduced by the extent of primary bonding (and the tertiary by the extent of primary and secondary and etc.). The reduction in secondary bonding, by primary bonding, is determined by the least primary bonding of the two secondary bonding orbitals. Thirdly, total overlap, including contributions from secondary and subsequent bonds, is calculated along the principle axis which is usually the primary bond axis.

The secondary (tertiary, etc.) overlap between the primary bonding orbital on the left and the secondary bonding orbital on the right is as follows:

$$
\begin{aligned}
& \text { overlap }_{\text {sec } \_l}=\mathrm{fs}_{\mathrm{bl}} \mathrm{fs}_{\mathrm{br}} \text { overlap }_{\mathrm{s}-\mathrm{s}}+\cos \theta_{1} \cos \theta_{\mathrm{r}} \mathrm{fp}_{\mathrm{bl}} \mathrm{fp}_{\mathrm{br}} \text { overlap }_{\mathrm{pz}-\mathrm{pz}}+ \\
& \cos \theta_{1} \mathrm{fp}_{\mathrm{bl}} \mathrm{fs}_{\mathrm{br}} \text { overlap } \mathrm{p}_{\mathrm{pz}-\mathrm{s}}+\cos \theta_{\mathrm{r}} \mathrm{fs}_{\mathrm{bl}} \mathrm{fp}_{\mathrm{br}} \text { overlap }_{\mathrm{s}-\mathrm{pz}} \text {, }
\end{aligned}
$$

where $\theta_{1}$ is the angle between the primary axis of the left atom and the secondary (tertiary, etc.) bond axis and where $\theta_{\mathrm{r}}$ is the angle between the primary axis of the right atom and the secondary (tertiary, etc.) bond axis. Notice that $\mathrm{fs}_{\mathrm{bl}}$ and $\mathrm{fp}_{\mathrm{bl}}$ refer to the hybridization of the primary orbital on the left and $\mathrm{fs}_{\mathrm{br}}$ and $\mathrm{fp}_{\mathrm{br}}$ refer to the hybridization of the secondary orbital on the right. Note also that, in general, the secondary for the left is different from the secondary on the right. The calculation of overlap sec_r $_{\text {r }}$ is analogous to that on the left. Sometimes there is a secondary on one side but none on the other (e.g. $\mathrm{CH}_{4}$ ).

The overlap component along the primary bond axis, overlapsec__z, is:

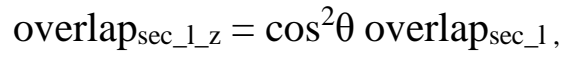

where $\theta$ is the angle between the primary bond axis and the secondary (tertiary, etc.) bond axis. The secondary fraction_bonding increment, fraction_bonding sec_l_inc, $_{\text {, is: }}$

$$
\begin{aligned}
& \text { fraction_bonding } g_{s e c \_l \_i n c}=0.5\left(1-\text { fraction_bonding } \text { lessor_primary_l}_{1}\right) \\
& \text { (overlap } \text { sec____z }_{\text {_t }}\left(1+\text { overlap }_{\text {sec____z }}\right)
\end{aligned}
$$

where fraction_bonding lessor_primary_l $_{\text {in }}$ is the lessor of the two fraction_bonding primary $_{\text {associated with }}$ the secondary. The factor of 0.5 arises because the secondary bond spans two primary bonds. The contribution of the secondary overlap to the total overlap, the secondary overlap increment,

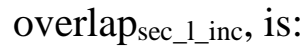

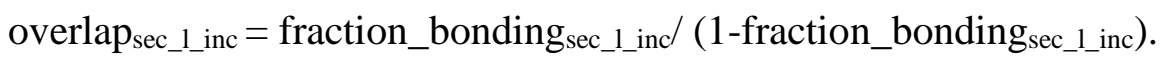


The calculations for the right side are analogous to those on the left. The overlap subtotal, overlap subtotal, is:

$$
\begin{aligned}
& \text { overlap }_{\text {subtotal }}=\text { overlap }_{\text {primary }}+\text { overlap } \\
& \text { frec_l_inctoverlap } \\
& \text { frec_r_inc, and }
\end{aligned}
$$

Subsequent, secondary (or tertiary and etc.) are treated similarly.

Summing overlap contributions in this manner is very important because they make up a very significant portion of the total overlap (typically around 10-25\%) and therefore have a very large impact on the bond length and, indirectly, via the overlap $\mathrm{total}_{1}=1.0$ constraint, on the bond energy. The direct secondary contributions to the bond energy (described below) can sometimes be ignored for an approximate result but the secondary contributions to overlap cannot be ignored.

The core orthogonalization penalty associated with the overlap of the primary bonding orbital on the left and the core electrons of the secondary atom on the right is as follows:

$$
\begin{aligned}
& \mathrm{KE}_{\text {core_ortho_sec_l }}=\left(\mathrm{fs}_{\mathrm{bl}} \mathrm{fs} \mathrm{s}_{\mathrm{br}} \mathrm{f} \mathrm{s}_{\mathrm{bl}} \mathrm{f} \mathrm{f}_{\mathrm{br}}\left(\mathrm{KE}_{\mathrm{s}_{-} \mathrm{sal}}-\mathrm{KE}_{\mathrm{sl}}\right)+\right. \\
& f_{s b l} f_{b r} f_{b l} f p_{b r}\left(K_{s_{s}} p z a l-K E_{s l}\right)+ \\
& \cos (\theta) \mathrm{fp}_{\mathrm{bl}} \mathrm{fs}_{\mathrm{br}} \mathrm{fp}_{\mathrm{bl}} \mathrm{fs} \text { br }\left(\mathrm{KE}_{\mathrm{pz} \_ \text {sal }}-\mathrm{KE}_{\mathrm{pzl}}\right)+ \\
& \left.\cos (\theta) f p_{b l} f p_{b r} f p_{b l} f p_{b r}\left(K E_{p z \_p z a l}-K_{p z l}\right)\right) \text {. }
\end{aligned}
$$

The calculations for the right side are analogous to those on the left. The core_orth contributions

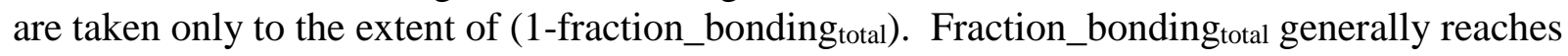
0.5. The $\mathrm{KE}_{\text {core_orth_sec }}$ contributions to the bond energy are generally quite small.

Secondary potential energy terms are calculated in the same manner as those of the primary terms. The secondary and subsequent contributions are much smaller than the primary

\begin{tabular}{|c|c|c|}
\hline Component & Value & $\begin{array}{l}\text { Overlap } \\
\text { Increment }\end{array}$ \\
\hline $\begin{array}{l}\text { Sigma overlap of primary orbitals (overlap } 1 \text { st) } \\
\text { overlap }_{1 s t}=0.25 \text { overlap }_{s-s}+0.25 \text { overlap }_{s-p}+0.25 \text { overlap }_{p-s}+0.25 \text { overlap } p-p \\
f_{s_{b r}}=\mathrm{fs}_{b l}=\mathrm{fp}_{\mathrm{br}}=\mathrm{fp}_{\mathrm{bl}}=0.5\end{array}$ & 0.7960 & 0.7960 \\
\hline $\begin{array}{l}\text { Fraction_bonding of primary (fraction_bonding } 1 \text { st }) \\
\quad \text { fraction_bonding }_{1 s t}=\text { overlap }_{1 s t} /\left(1+\text { overlap }_{1 s t}\right)\end{array}$ & 0.4432 & \\
\hline
\end{tabular}
due to the longer atomic distances, but they are nonetheless usually significant.

Table V provides a complete breakdown of the many components that contribute to the total overlap in diamond.

\section{Table V. Components of the Calculation of Overlap in Diamond at $1.541 \AA$}

The configuration of $C$ in diamond is $1 s^{2} 2 s 2 p_{z} 2 p_{x y}{ }^{2}$. 


\begin{tabular}{|c|c|c|}
\hline Component & Value & $\begin{array}{l}\text { Overlap } \\
\text { Increment }\end{array}$ \\
\hline $\begin{array}{l}\left.\text { Sigma overlap to secondary along primary axis (overlap } 2_{n d}\right) \\
3 \text { secondary atoms are at }(0,1 / 2,1 / 2) \text { at } 2.517 \AA \\
\text { The angle from bond axis is } 35.265 \text { degrees. } \cos (35.265)=0.8165 \\
\text { overlap } 2_{n d}=0.81650 .8165\left(0.25 \text { overlap }_{s-s}+0.81650 .25 \text { overlap }_{s-p}+\right. \\
\left.0.81650 .25 \text { overlap }_{p-s}+0.81650 .8165 \cdot 0.25 \text { overlap }_{p-p}\right)\end{array}$ & 0.0949 & \\
\hline $\begin{array}{l}\text { Secondary fraction_bonding (fraction_bonding } 2 \text { nd }) \\
\text { fraction_bonding } 2 \text { nd }=\text { overlap }_{2 \text { nd }} /\left(1+\text { overlap }_{2 n d}\right)\end{array}$ & 0.0867 & \\
\hline $\begin{array}{l}\text { First secondary fraction_bonding increment (fraction_bonding } 2 \text { nd_inc) } \\
\left.\text { fraction_bonding }{ }_{2 n d i n c}=20.5 \text { ( } 1 \text { - fraction_bonding }{ }_{1 s t}\right) \text { fraction_bonding }{ }_{2 \text { nd }} \\
\text { Secondary fraction_bonding is reduced by previous, coincident, } 1^{\text {st }} \text { order bonding. } \\
0.5 \text { because secondary spans } 2 \text { primary } \\
2 \text { because primary } C \text { is also a secondary }\end{array}$ & 0.0483 & \\
\hline $\begin{array}{l}\text { First secondary overlap } \\
\quad \text { first secondary overlap = fraction_bonding2nd_inc/(1- fraction_bonding 2nd_inc) }\end{array}$ & 0.0507 & \\
\hline $\begin{array}{l}\text { Total secondary overlap for } 3 \text { atoms } \\
\text { Note that coincident bonding increases as previous fraction_bonding } \\
\text { increases with successive bonds. } 0.1479<30.0507\end{array}$ & 0.1479 & 0.1479 \\
\hline $\begin{array}{l}\left.\text { Sigma overlap to tertiary } \# 1 \text { (overlap } 3_{r d} \# 1\right) \\
6 \text { tertiary atoms are at }(1 / 4,3 / 4,-1 / 4) \text { and }(3 / 4,1 / 4,-1 / 4) \text { at } 2.9512 \AA \\
\text { cos }(\text { angle })=0.5222 \\
\text { overlap } 3_{r d} \# 1=0.52220 .5222\left(0.25 \text { overlap }_{s-s}+0.52220 .25 \text { overlap }_{s-p}+\right. \\
\left.0.52220 .25 \text { overlap }_{p-s}+0.52220 .52220 .25 \text { overlap }_{p-p}\right)\end{array}$ & 0.0108 & \\
\hline Total tertiary overlap \#1 for 6 atoms & 0.0329 & 0.0329 \\
\hline $\begin{array}{l}\text { Sigma overlap to tertiary } \# 2 \text { (overlap } 3_{\text {rd }} \# 2 \text { ) } \\
3 \text { tertiary atoms are at }(1 / 4,3 / 4,3 / 4 \text { ) at } 3.8781 \AA \\
\cos (\text { angle })=0.9270\end{array}$ & 0.0089 & \\
\hline Total tertiary overlap \#2 for 3 atoms & 0.0134 & 0.0134 \\
\hline $\begin{array}{l}\text { Sigma overlap to tertiary } \# 3 \text { (overlap } 3 \text { rd } \# 3 \text { ) } \\
7 \text { tertiary atoms are at opposite faces at } 4.3592 \AA \text { ( } 4 \text { above unit cell) } \\
\cos (\text { angle })=0.4717\end{array}$ & 0.0004 & \\
\hline Total tertiary overlap \#3 for 7 atoms & 0.0013 & 0.0013 \\
\hline $\begin{array}{l}\text { Sigma overlap to tertiary \#4 (overlap } 3 \text { rd \#4) } \\
3 \text { tertiary atoms are at adjacent corner at } 3.5593 \AA \\
\cos (\text { angle })=0.5774\end{array}$ & 0.0041 & \\
\hline Total tertiary overlap \#4 for 3 atoms & 0.0061 & 0.0061 \\
\hline $\begin{array}{l}\text { Sigma overlap to tertiary \#5 (overlap } 3 \text { rd } \# 5 \text { ) } \\
3 \text { tertiary atoms are at one off from adjacent corner at } 5.5372 \AA \\
\cos (\text { angle })=0.7360\end{array}$ & 0.0009 & \\
\hline Total tertiary overlap \#5 for 3 atoms & 0.0014 & 0.0014 \\
\hline
\end{tabular}




\begin{tabular}{|c|c|c|}
\hline Component & Value & $\begin{array}{l}\text { Overlap } \\
\text { Increment }\end{array}$ \\
\hline $\begin{array}{l}\left.\text { Sigma overlap to tertiary } \# 6 \text { (overlap } 3_{r d} \# 6\right) \\
3 \text { tertiary atoms are at corners at }(1,1,0),(1,0,1) \text { and }(0,1,1) \text { at } 5.0336 \AA \\
\cos (\text { angle })=0.8167\end{array}$ & 0.0004 & \\
\hline Total tertiary overlap \#6 for 3 atoms & 0.0006 & 0.0006 \\
\hline $\begin{array}{l}\text { Sigma overlap to tertiary \#7 (overlap } 3_{\text {rd }} \# 7 \text { ) } \\
3 \text { tertiary atoms are at opposite corners at } 6.165 \AA \\
\cos (\text { angle })=0.8167\end{array}$ & 0.0000 & \\
\hline Total tertiary overlap \#7 for 3 atoms & & 0.0001 \\
\hline Total Overlap & & 0.9997 \\
\hline
\end{tabular}

\section{RESULTS}

Some results from the application of the methods described herein are presented in Tables VI, VII and VIII. Table IX provides a description of the components of the $\mathrm{C}_{2}$ calculation. Table $\mathrm{X}$ is a detailed description of the components of the $\mathrm{CH}_{4}$ calculation.

Bond lengths are generally accurate to $0.005 \AA$ and bond energies to a few percent. Except for a few bonds to hydrogen, the bond length results are independent of the bond energy results. Of these results, only for $\mathrm{H}_{2}$ is the bond length determined by a maximum in the bond length versus bond energy curve. Otherwise the bond length is found at the point where overlap becomes 1.0 (and fraction_bonding becomes 0.5 ) as the bond length is decreased.

Aside from the character of the original atomic orbital, bond lengths are impacted only by core orthogonalization and the selected orbital scale factor. Finding the optimum parameters for the core orthogonalization, using the analytical procedures described above, particularly for $\mathrm{C}$ through $\mathrm{F}$, is not difficult. Bond lengths are not sensitive to small changes from the optimal orthogonalization parameters although care must be taken in the core orthogonalization to assure accurate bond energies. Orbital scale factors are generally easy to establish as the energy required to compress an atomic orbital rises rapidly with the factor. The factors used are shown in the results tables for comparison purposes. Consistent with the data in Table I, the factors are larger for lighter elements. Orbital scale factors for poly-coordinate atoms are larger than those of di-atomics because the energy to compress the orbital is spread among several bonds.

Bond energies are sensitive to the magnitude of the stop value. Care has been taken to use the same stop value in different compounds in which the atom shows a similar electronic structure. The stop values used for each bond are shown in the results tables for comparison purposes.

The results tables provide the bonding and not bonding configurations of the bonding atoms. In these tables $2 \mathrm{sp}_{0}$ indicates an opposing orbital and $2 \mathrm{sp}$ is a hybrid orbital made by adding a small amount of $2 \mathrm{p}$ to a $2 \mathrm{~s}$ orbital. The $\mathrm{z}$ axis is taken as the bond axis. Notice that in $\mathrm{O}_{2}$ and $\mathrm{O}_{2}^{-}$, the bonding configurations include two $2 \mathrm{p}_{\mathrm{z}}$. One of these is reconfigured as $2 \mathrm{p}_{\perp}$ (or more precisely, $2 \mathrm{p}_{\pi}$ since there is pi bonding here) in the not bonding configuration. In $\mathrm{CH} 3$ and graphite, one of the C atom's $2 \mathrm{~s}$ orbitals is promoted to $2 \mathrm{p}_{\perp}$ when any of the central $\mathrm{C}$ atom's 3 bonds is not bonding $[(1.0-0.50 .50 .5)=0.875]$ to meet the orthogonality requirement. In graphite, this promotion allows pi bonding when the $\mathrm{C}$ atoms on both sides of the bond are not 
bonding $(0.8750 .875)$. In graphite pi bonding is reduced by the extent of simultaneous pi bonding to other Cs.

Hybridization of the bonding orbitals on central atoms in poly-atomics is different from that in di-atomic molecules or terminal atoms. The hybridization of bonding orbitals on atoms that are not in the terminal position is determined via the availability of s character. In threecoordinate $\mathrm{CH}_{3}$ ( $\mathrm{D}_{3 \mathrm{~h}}$ symmetry) and graphite, the square of the central $\mathrm{C}$ bonding orbital s coefficient, $\mathrm{fs}_{\mathrm{b}} \mathrm{fs}_{\mathrm{b}}$, is 0.667 . The s character in the bonding orbital cannot be oversubscribed, so 3 fraction_bonding $\mathrm{fs}_{\mathrm{b}} \mathrm{fs}_{\mathrm{b}}$ must be less than or equal to 1.0 and, since fraction_bonding $=0.5$, f $\mathrm{s}_{\mathrm{b}}$ $\mathrm{fs}_{\mathrm{b}}=0.667$. The $\mathrm{s}$ character in a bonding orbital is maximized because this leads to a lessor orbital overlap and a shorter bond. Following the same logic, four-coordinate atoms or pseudo four-coordinate central atoms (those which have a combination of four lone pairs and bonds) have $\mathrm{fs}_{\mathrm{b}} \mathrm{fs}_{\mathrm{b}}=0.5$. Diamond and methane have four-coordinate central atoms and have $\mathrm{T}_{\mathrm{d}}$ symmetry. Water and ammonia are pseudo four-coordinate. Two-coordinate atoms such as $\mathrm{CO}_{2}$ have $\mathrm{fs}_{\mathrm{b}} \mathrm{fs}_{\mathrm{b}}=0.75$. In the two-coordinate case, the $\mathrm{s}$ character of the central atom's orbital is limited because, when both sides are not bonding, 0.25 of the time, $f_{b} f_{s}$ must equal 0.5 .

Consistent with the traditional view, $\mathrm{NH}_{3}$ and $\mathrm{H}_{2} \mathrm{O}$ have one and two traditional $\mathrm{sp}^{3}$ orbitals containing lone (non-bonding) pairs of electrons respectively. The bond axes in these molecules are bent inward relative to the electronic axes to make the lone pair(s) orthogonal to the $\mathrm{H} 1 \mathrm{~s}$ bonding orbital. The calculated bond angles reflect the requisite bending.

Dipole moments, $\mu$, have been calculated for $\mathrm{NO}, \mathrm{NH}_{3}$ and $\mathrm{H}_{2} \mathrm{O}$. Dipole moments are very sensitive to the electronic structure of the molecule. The calculated values are in good agreement with the observed values.

Table VI. Results for Some Di-Atomics Which Exhibit No Resonance

\begin{tabular}{|c|c|c|c|c|c|}
\hline Molecule & $\mathrm{De}_{\mathrm{a}}^{\mathrm{a}}$ or $\mathrm{D}_{0}^{\mathrm{b}} / \mathrm{eV}$ & $\begin{array}{c}\text { Bond } \\
\text { Length/A }\end{array}$ & $\begin{array}{l}\text { Configurations }{ }^{c, d, e, f} \\
\text { (C to } 01 s^{2} \text { omitted) }\end{array}$ & Bonds & $\begin{array}{c}\text { stop/ } \\
\text { eV }\end{array}$ \\
\hline $\mathrm{H}_{2}$ & $\begin{array}{l}\text { observed } \\
4.75 \\
\text { calculated } \\
4.67\end{array}$ & $\begin{array}{l}\text { observed } \\
0.741 \\
\text { calculated } \\
0.754\end{array}$ & $\begin{array}{c}\mathrm{H} \text { 1s }\left(\text { polarized } \mathrm{w} / \mathrm{p}_{z}\right) \\
\mathrm{H} \mathrm{f \textrm {s } _ { \mathrm { b } }} \cdot \mathrm{fs}_{\mathrm{b}}=0.992 \\
\text { fact }_{1 \mathrm{~s}}=1.15 \\
\text { fact }_{2 \mathrm{pz}}=3.5\end{array}$ & $\sigma$ & $\mathrm{n} / \mathrm{a}$ \\
\hline $\mathrm{C}_{2}$ & $\begin{array}{l}\text { observed } \\
6.3 \\
\text { calculated } \\
6.51\end{array}$ & $\begin{array}{l}\text { observed } \\
1.2425 \\
\text { calculated } \\
1.243\end{array}$ & $\begin{array}{c}\text { bonding } C 2 \mathrm{sp}^{2} 2 \mathrm{p}_{\pi}^{2} \\
\text { not bonding } 2 \mathrm{sp}_{\mathrm{o}} 2 \mathrm{sp} 2 \mathrm{p}_{\pi}^{2} \\
\text { fact }_{2 \mathrm{~s}, 2 \mathrm{p}}=1.035\end{array}$ & $\begin{array}{c}2 \sigma(\text { dual }) \\
\mathrm{fs}_{b} \mathrm{fs}_{b}=0.957 \\
2 \pi\end{array}$ & $\begin{array}{c}6.55 \\
\text { (unpaired) }\end{array}$ \\
\hline $\mathrm{N}_{2}$ & $\begin{array}{c}9.91 \\
\text { calculated } \\
9.80\end{array}$ & $\begin{array}{c}1.0977 \\
\text { calculated } \\
1.100\end{array}$ & $\begin{array}{c}\text { bonding } 2 \mathrm{~s}^{2} 2 \mathrm{p}_{\mathrm{z}} 2 \mathrm{p}_{\pi}^{2} \\
\text { not bonding } 2 \mathrm{sp}_{\mathrm{o}} 2 \mathrm{~s} 2 \mathrm{p}_{\mathrm{z}} 2 \mathrm{p}_{\pi}^{2} \\
\text { fact } 2 \mathrm{~s}, 2 \mathrm{p}^{2}=1.015\end{array}$ & $\begin{array}{c}2 \sigma(\text { dual }) \\
2 \pi\end{array}$ & 12.40 \\
\hline $\mathrm{BN}$ & $\begin{array}{c}\text { observed } \\
3.92 \\
\pm 0.08 \\
\text { calculated } \\
4.00\end{array}$ & $\begin{array}{l}\text { observed } \\
1.281 \\
\text { calculated } \\
1.281\end{array}$ & $\begin{array}{c}\text { bonding } B 2 s^{2} 2 p_{z} \\
\text { not bonding } B 2 s p_{o} 2 s 2 p_{z} \\
\text { bonding } N 2 s^{2} 2 p_{z} 2 p_{\perp}^{2} \\
\text { not bonding } N \\
2 s p_{\circ} 2 s 2 p_{z} 2 p_{\perp}^{2} \\
\operatorname{fact}_{2 s, 2 p}(B, N)=1.04,1.015\end{array}$ & $\begin{array}{c}2 \sigma(\text { dual }) \\
\text { no } \pi\end{array}$ & $\begin{array}{c}\text { B } 6.55 \\
\text { N } 12.40\end{array}$ \\
\hline
\end{tabular}




\begin{tabular}{|c|c|c|c|c|c|}
\hline Molecule & $\mathrm{De}_{\mathrm{e}}^{\mathrm{a}}$ or $\mathrm{D}_{0}^{\mathrm{b}} / \mathrm{eV}$ & $\begin{array}{c}\text { Bond } \\
\text { Length/Å }\end{array}$ & $\begin{array}{l}\text { Configurations } s^{c, d, e, f} \\
\text { (C to } 01 s^{2} \text { omitted) }\end{array}$ & Bonds & $\begin{array}{l}\text { stop/ } \\
\text { eV }\end{array}$ \\
\hline $\mathrm{CN}$ & $\begin{array}{c}\text { observed } \\
7.78 \\
\pm 0.03 \\
\text { calculated } \\
7.67\end{array}$ & $\begin{array}{c}\text { observed } \\
1.172 \\
\text { calculated } \\
1.169\end{array}$ & $\begin{array}{c}\text { bonding } C 2 \mathrm{sp}^{2} 2 \mathrm{p}_{\pi}^{2} \\
\text { bonding } \mathrm{N} 2 \mathrm{~s}^{2} 2 \mathrm{p}_{\mathrm{z}} 2 \mathrm{p}_{\pi}^{2} \\
\text { not bonding } C 2 \mathrm{sp}_{\mathrm{o}} 2 \mathrm{sp} 2 \mathrm{p}_{\pi}^{2} \\
\text { not bonding } \mathrm{N} \\
2 \mathrm{sp}_{\mathrm{o}} 2 \mathrm{~s} 2 \mathrm{p}_{\mathrm{z}} 2 \mathrm{p}_{\pi}^{2} \\
\text { fact }_{2 \mathrm{~s}, 2 \mathrm{p}}(\mathrm{C}, \mathrm{N})=1.035,1.01\end{array}$ & $\begin{array}{c}2 \sigma \text { (dual) } \\
C \mathrm{fs}_{\mathrm{b}} \mathrm{fs}_{\mathrm{b}}=0.953 \\
2 \pi\end{array}$ & $\begin{array}{c}\text { C } 6.55 \\
\text { (unpaired) } \\
\text { N } 12.40\end{array}$ \\
\hline NO & $\begin{array}{c}\text { observed } \\
6.56 \\
\text { calculated } \\
6.42 \\
\\
\left(\mu_{\text {calc }}=0.133 \mathrm{D}\right. \\
\left.\mu_{\text {expt }}=0.159 \mathrm{D}\right)\end{array}$ & $\begin{array}{c}\text { observed } \\
1.1506 \\
\text { calculated } \\
1.154\end{array}$ & $\begin{array}{c}\text { bonding } N 2 s^{2} 2 p_{z} 2 p_{\pi}^{2} \\
\text { bonding } O 2 s^{2} 2 p_{z}^{2} 2 p_{\pi}^{3} \\
\text { not bonding } N \\
2 s p_{o} 2 s 2 p_{z} 2 p_{\pi}^{2} \\
\text { not bonding } O \\
2 s_{o} 2 s_{2} 2 p_{z} 2 p_{\pi}^{2} 2 p_{\pi a} \\
\text { fact } 2 s, 2 \mathrm{p}(N, O)=1.02,1.02\end{array}$ & $\begin{array}{c}2 \sigma(\text { dual }) \\
2 \pi\end{array}$ & $\begin{array}{l}\text { N } 12.40 \\
\text { O } 16.60\end{array}$ \\
\hline
\end{tabular}

${ }^{\text {a }}$ Homonuclear di-atomics. $\mathrm{D}_{\mathrm{e}}$ is the equilibrium dissociation energy which is slightly larger than the molecular ground-state-dissociation energy $\mathrm{D}_{0}$. Observed data are from Ira N. Levine, Quantum Chemistry $7^{\text {th }}$ edition, pp 373, Pearson (2014) and/or John P. Lowe, Quantum Chemistry $2^{\text {nd }}$ edition, pp 224, Academic Press (1993).

${ }^{\mathrm{b}}$ Heteronuclear di-atomics. Observed $\mathrm{D}_{0}$ data are from W.M. Hayes, Editor in Chief, CRC Handbook of Chemistry and Physics, Section 9, CRC Press (2014).

${ }^{\mathrm{c}}$ fact is the orbital scale factor.

${ }^{d} 2$ sp is a hybrid orbital made by adding a small amount of $2 p$ to the existing 2 s orbital.

e $2 \mathrm{sp}_{\mathrm{o}}$ is a hybrid opposing orbital formed to meet the valence orthogonalization requirement.

${ }^{\mathrm{f}} 2 \mathrm{p}_{\pi \mathrm{a}}$ is $2 \mathrm{p}_{\pi}$ made orthogonal to opposite $2 \mathrm{p}$.

Table VII. Results for Some Di-Atomics Which Exhibit a Full Pi Resonance

\begin{tabular}{|c|c|c|c|c|c|}
\hline Molecule & $D_{e}{ }^{a} / e V$ & $\begin{array}{c}\text { Bond } \\
\text { Length/Å }\end{array}$ & $\begin{array}{l}\text { Configurations } s^{b, c, d, e} \\
\left(1 s^{2} \text { omitted }\right)\end{array}$ & Bonds & $\begin{array}{l}\text { stop/ } \\
\text { eV }\end{array}$ \\
\hline $\mathrm{B}_{2}$ & $\begin{array}{l}\text { observed } \\
3.1 \\
\text { calculated } \\
3.21\end{array}$ & $\begin{array}{l}\text { observed } \\
1.590 \\
\text { calculated } \\
1.582\end{array}$ & $\begin{array}{l}\text { bonding B } 2 \mathrm{sp}^{2} 2 \mathrm{p}_{\pi} \\
\text { bonding } \mathrm{B}+2 \mathrm{sp}^{2} \\
\text { bonding } \mathrm{B}-2 \mathrm{sp}^{2} 2 \mathrm{p}_{\pi}^{2} \\
\text { not bonding } \mathrm{B}+, \mathrm{B}, \mathrm{B}- \\
2 \mathrm{sp}_{\mathrm{o}} 2 \mathrm{sp} 2 \mathrm{p}_{\pi}^{0,1,2} \\
\text { fact }_{2 \mathrm{~s}, 2 \mathrm{p}}=1.035\end{array}$ & $\begin{array}{c}2 \sigma \text { (dual) } \\
\mathrm{fs}_{\mathrm{b}} \mathrm{fs}_{\mathrm{b}}=0.953 \\
\pi_{\text {resonance }}\end{array}$ & $\begin{array}{c}4.35 \\
\text { (unpaired) }\end{array}$ \\
\hline $\mathrm{C}_{2}^{+}$ & $\begin{array}{l}\text { observed } \\
5.3 \\
\text { calculated } \\
5.22\end{array}$ & $\begin{array}{c}\text { observed } \\
1.301 \\
\text { calculated } \\
1.301\end{array}$ & $\begin{array}{c}\text { bonding } C 2 \mathrm{sp}^{2} 2 \mathrm{p}_{\pi}^{2} \\
\text { bonding } \mathrm{C}+2 \mathrm{sp}^{2} 2 \mathrm{p}_{\pi} \\
\text { not bonding } 2 \mathrm{sp}_{0} 2 \mathrm{sp} 2 \mathrm{p}_{\pi}^{1.2} \\
\text { fact } 2 \mathrm{~s}, 2 \mathrm{p}(\mathrm{C}, \mathrm{C}+\mathrm{C})=1.08\end{array}$ & $\begin{array}{c}2 \sigma \text { (dual) } \\
\mathrm{fs}_{\mathrm{b}} \mathrm{fs}_{\mathrm{b}}=0.915 \\
\pi_{\text {resonance }}\end{array}$ & $\begin{array}{c}\text { C } 6.55 \\
\text { (unpaired) } \\
\text { C+ } 4.35 \\
\text { (unpaired) }\end{array}$ \\
\hline $\mathrm{O}_{2}$ & $\begin{array}{l}\text { observed } \\
5.21 \\
\text { calculated } \\
5.25\end{array}$ & $\begin{array}{c}\text { observed } \\
1.2074 \\
\text { calculated } \\
1.208\end{array}$ & $\begin{array}{c}\text { bonding } \mathrm{O}+, \mathrm{O}, \mathrm{O}- \\
2 \mathrm{~s}^{2} 2 \mathrm{p}_{\mathrm{z}}{ }^{2} 2 \mathrm{p}_{\pi}^{1,2,3} \\
\text { not bonding } \mathrm{O}+, \mathrm{O}, \mathrm{O}- \\
2 \mathrm{sp}_{\mathrm{o}} 2 \mathrm{~s}_{2} \mathrm{p}_{\mathrm{z}} 2 \mathrm{p}_{\pi}^{2,2,2} 2 \mathrm{p}_{\pi \mathrm{a}} \mathrm{O}, 1,2 \\
\text { fact }_{2 \mathrm{~s}, 2 \mathrm{p}}=1.0225\end{array}$ & $\begin{array}{c}2 \sigma \text { (dual) } \\
\mathrm{fs}_{\mathrm{b}} \mathrm{fs}_{\mathrm{b}}=0.40 \\
2 \pi_{\text {resonance }} \text { plus } \pi \\
\text { plus } \pi \text { when both } \\
\text { sides } \mathrm{s} \Rightarrow p\end{array}$ & 16.60 \\
\hline
\end{tabular}




\begin{tabular}{|c|c|c|c|c|c|}
\hline Molecule & $D_{e}{ }^{a} / e V$ & $\begin{array}{c}\text { Bond } \\
\text { Length/Å }\end{array}$ & $\begin{array}{l}\text { Configurations } s^{b, c, d, e} \\
\left(1 s^{2} \text { omitted }\right)\end{array}$ & Bonds & $\begin{array}{l}\text { stop/ } \\
\text { eV }\end{array}$ \\
\hline $\mathrm{O}_{2}^{-}$ & $\begin{array}{l}\text { observed } \\
4.14 \\
\text { calculated } \\
4.11\end{array}$ & $\begin{array}{c}\text { observed } \\
1.32 \\
\text { calculated } \\
1.28\end{array}$ & $\begin{array}{c}\text { bonding } \mathrm{O}, \mathrm{O}- \\
2 \mathrm{~s}^{2} 2 \mathrm{p}_{\mathrm{z}}{ }^{2} 2 \mathrm{p}_{\pi}^{2,2} 2 \mathrm{p}_{\pi \mathrm{a}}^{0,1} \\
\text { not bonding } \mathrm{O}, \mathrm{O}- \\
2 \mathrm{sp}_{\mathrm{o}} 2 \mathrm{~s} 2 \mathrm{p}_{\mathrm{z}} 2 \mathrm{p}_{\pi}^{2,2} 2 \mathrm{p}_{\pi \mathrm{a}}{ }^{1,2} \\
\operatorname{fact}_{2 \mathrm{~s}, 2 \mathrm{p}}(\mathrm{O}, \mathrm{O}-)=0.965\end{array}$ & $\begin{array}{c}2 \sigma \text { (dual) } \\
\mathrm{fs}_{b} \mathrm{fs}_{\mathrm{b}}=0.46 \\
\pi_{\text {resonance }} \text { plus } \\
2 \pi\end{array}$ & $\begin{array}{l}\text { O } 16.60 \\
\text { o- } 16.60\end{array}$ \\
\hline$F_{2}$ & $\begin{array}{l}\text { observed } \\
1.66 \\
\text { calculated } \\
1.74\end{array}$ & $\begin{array}{c}\text { observed } \\
1.412 \\
\text { calculated } \\
1.418\end{array}$ & $\begin{array}{c}\text { bonding } \mathrm{F} \\
2 \mathrm{~s}^{2} 2 \mathrm{p}_{\mathrm{z}}^{2} 2 \mathrm{p}_{\pi}^{2} 2 \mathrm{p}_{\pi \mathrm{a}} \\
\text { not bonding } \mathrm{F} \\
2 \mathrm{sp}_{0} 2 \mathrm{~s}_{2} \mathrm{p}_{\mathrm{z}} 2 \mathrm{sp}_{\mathrm{a}} 2 \mathrm{p}_{\pi}^{2} 2 \mathrm{p}_{\pi \mathrm{a}} \\
\text { fact }_{2 \mathrm{~s}, 2 \mathrm{p}}=1.01\end{array}$ & $\begin{array}{c}2 \sigma \text { (parallel) } \\
\text { fraction_bond }=0.25 \\
\text { for each of two } \sigma \\
2 \pi_{\text {resonance }} \text { plus } 2 \pi\end{array}$ & $\mathrm{n} / \mathrm{a}$ \\
\hline
\end{tabular}

a $\mathrm{D}_{\mathrm{e}}$ is the equilibrium dissociation energy. Observed data are from Ira N. Levine, Quantum Chemistry $7^{\text {th }}$ edition, pp 373, Pearson (2014) and/or John P. Lowe, Quantum Chemistry $2^{\text {nd }}$ edition, pp 224, Academic Press (1993).

${ }^{\mathrm{b}}$ fact is the orbital scale factor.

${ }^{c} 2 s p$ is a hybrid orbital made by adding a small amount of $2 p$ to the existing 2 s orbital.

${ }^{\mathrm{d}} 2 \mathrm{sp}_{\mathrm{o}}$ is a hybrid opposing orbital formed to meet the valence orthogonalization requirement.

${ }^{\mathrm{e}} 2 \mathrm{p}_{\pi \mathrm{a}}$ is $2 \mathrm{p}_{\pi}$ made orthogonal to opposite $2 \mathrm{p}$.

Table VIII. Some Poly-atomics

\begin{tabular}{|c|c|c|c|c|c|}
\hline Molecule & $\begin{array}{c}D_{\circ}^{a, b} / e V \\
\mu / D\end{array}$ & $\begin{array}{l}\text { Bond } \\
\text { Lengthc/̊̊ } \\
\angle^{c} /{ }^{\circ}\end{array}$ & $\begin{array}{c}\text { Configurations }^{d} \\
\left(1 s^{2} \text { omitted }\right)\end{array}$ & Bonds & stop/eV \\
\hline $\begin{array}{l}\mathrm{CH} / \mathrm{CH}_{3} \\
\text { (methyl) }\end{array}$ & $\begin{array}{c}\text { observed } \\
4.22 \\
\text { calculated } \\
4.25\end{array}$ & $\begin{array}{c}\text { observed } \\
1.076 \\
\text { calculated } \\
1.080\end{array}$ & $\begin{array}{l}\text { all bonding } C(0.125) \\
2 \mathrm{~s}^{2} 2 \mathrm{p}_{\mathrm{z}} 2 \mathrm{p}_{\perp} \\
\text { otherwise } 2 \mathrm{~s} 2 \mathrm{p}_{\mathrm{z}} 2 \mathrm{p}_{\perp}{ }^{2} \\
\operatorname{fact}_{2 \mathrm{~s}, 2 \mathrm{p}}(\mathrm{C})=1.05 \\
\operatorname{fact}_{1 \mathrm{~s}}(\mathrm{H})=1.08\end{array}$ & $\begin{array}{c}\sigma \\
C \mathrm{fs}_{b} \mathrm{fs}_{b}=0.6667 \\
\mathrm{H} \text { polarized } \\
\mathrm{H} \mathrm{fs}_{b} \cdot \mathrm{fs}_{\mathrm{b}}=0.977\end{array}$ & 6.95 \\
\hline $\mathrm{CO} / \mathrm{CO}_{2}$ & $\begin{array}{c}\text { observed } \\
8.33 \\
\text { calculated } \\
8.33\end{array}$ & $\begin{array}{c}\text { observed } \\
1.160 \\
\text { calculated } \\
1.160\end{array}$ & 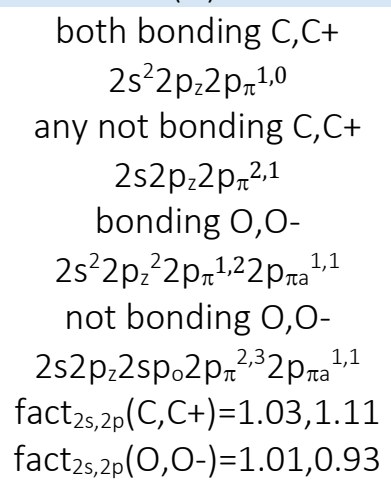 & $\begin{array}{c}\sigma \text { (dual when opposite } \\
\text { bonding i.e. } \mathrm{s} \nRightarrow \mathrm{p}_{\pi} \text { ) } \\
\mathrm{C} \mathrm{fs}_{\mathrm{b}} \mathrm{fs}_{\mathrm{b}}=0.75 \\
\pi \text { resonance } \\
{[\mathrm{O}-\mathrm{C}+\mathrm{O}, \mathrm{OCO}, \mathrm{OC}+\mathrm{O}-]} \\
\pi \text { bond (reduced for } \\
\text { coincident } \pi \text { ) } \\
\text { when } \mathrm{s} \Rightarrow \mathrm{p}_{\pi}(\mathrm{i} . \mathrm{e} \text {. } \\
\text { one/both not sigma } \\
\text { bonding) }\end{array}$ & $\begin{array}{l}C 7.50 \\
C+5.05 \\
\\
O 16.60 \\
O-16.60\end{array}$ \\
\hline $\begin{array}{l}\mathrm{CH} / \mathrm{CH}_{4} \\
\text { (methane) }\end{array}$ & $\begin{array}{c}\text { observed } \\
4.30 \\
\text { calculated } \\
4.32\end{array}$ & $\begin{array}{c}\text { observed } \\
1.087 \\
\text { calculated } \\
1.104\end{array}$ & $\begin{array}{c}C \\
2 \mathrm{~s} 2 \mathrm{p}_{z} 2 \mathrm{p}_{\perp}{ }^{2} \\
\operatorname{fact}_{2 \mathrm{~s}, 2 \mathrm{p}}(\mathrm{C})=1.05 \\
\operatorname{fact}_{1 \mathrm{~s}}(\mathrm{H})=1.13\end{array}$ & 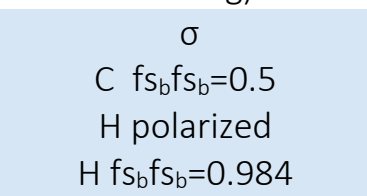 & 6.55 \\
\hline
\end{tabular}




\begin{tabular}{|c|c|c|c|c|c|}
\hline Molecule & $\begin{array}{c}D_{o}{ }^{a, b} / e V \\
\mu / D\end{array}$ & $\begin{array}{l}\text { Bond } \\
\text { Lengthc/Å } \\
\angle^{c} /{ }^{\circ}\end{array}$ & $\begin{array}{l}\text { Configurations }^{\mathrm{d}} \\
\left(1 \mathrm{~s}^{2} \text { omitted }\right)\end{array}$ & Bonds & stop/eV \\
\hline $\begin{array}{l}\mathrm{NH} / \mathrm{NH}_{3} \\
\text { (ammonia) }\end{array}$ & $\begin{array}{c}\text { observed } \\
4.05 \\
\mu_{\text {expt }} \\
=1.471 \\
\text { calculated } \\
4.16 \\
\mu_{\text {calc }}=1.47\end{array}$ & $\begin{array}{c}\text { observed } \\
1.012 \\
\angle \mathrm{HNH}= \\
106.7 \\
\text { calculated } \\
1.023 \\
\angle \mathrm{HNH}= \\
106.8\end{array}$ & $\begin{array}{c}N \\
2 s 2 p_{z} \\
2 p_{\perp}^{2+0.5} 2 \mathrm{sp}_{0}^{0.5} \\
\operatorname{fact}_{2 s, 2 p}(N)=1.01 \\
\operatorname{fact}_{1 s}(H)=1.17\end{array}$ & 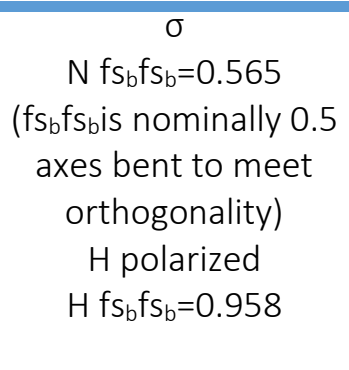 & 12.40 \\
\hline $\begin{array}{l}\mathrm{OH} / \mathrm{OH}_{2} \\
\text { (water) }\end{array}$ & $\begin{array}{c}\text { observed } \\
4.79 \\
\mu_{\text {expt }}=1.854 \\
\text { calculated } \\
4.79 \\
\mu_{\text {calc }}=1.83\end{array}$ & $\begin{array}{c}\text { observed } \\
0.9575 \\
\angle \mathrm{HOH}= \\
104.5 \\
\text { calculated } \\
0.923 \\
\angle \mathrm{HOH}= \\
104.5\end{array}$ & $\begin{array}{c}0 \\
2 s^{1+0.25} 2 p_{z} \\
2 p_{\perp}^{3+0.25} 2 \mathrm{sp}_{0}^{0.5} \\
\operatorname{fact}_{2 s, 2 p}(O)=1.01 \\
\operatorname{fact}_{1 s}(H)=1.16\end{array}$ & 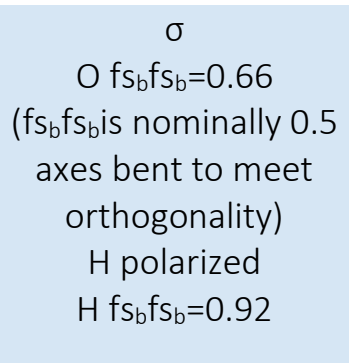 & 16.60 \\
\hline $\begin{array}{l}\mathrm{CC} / \\
\mathrm{C}_{3} \mathrm{CCC}_{3} \\
\text { (diamond) }\end{array}$ & $\begin{array}{c}\text { observed } \\
3.70 \\
\text { calculated } \\
3.71\end{array}$ & $\begin{array}{c}\text { observed } \\
1.544 \\
\text { calculated } \\
1.541\end{array}$ & $\begin{array}{c}2 s 2 p_{z} 2 p_{\perp}^{2} \\
f s_{b} f s_{b}=0.5 \\
2 s \text { is promoted to } 2 p \\
(s \Rightarrow p) \text { completely } \\
\text { fact }_{2 s, 2 p}(C)=1.055\end{array}$ & $C \mathrm{fs}_{b} \times \mathrm{fs}_{\mathrm{b}}=0.5$ & 6.55 \\
\hline $\begin{array}{l}\mathrm{CC} / \\
\mathrm{C}_{2} \mathrm{CCC}_{2} \\
\text { (graphite) }\end{array}$ & $\begin{array}{l}\text { observed } \\
\quad 4.95 \\
\text { calculated } \\
\text { in-plane } \\
4.79\end{array}$ & $\begin{array}{c}\text { observed } \\
1.421 \\
\text { calculated } \\
1.421\end{array}$ & $\begin{array}{c}\text { all bonding }(0.125) \\
2 s^{2} 2 p_{z} 2 p_{\perp} \\
\text { any not bonding }(0.875) \\
2 s 2 p_{z} 2 p_{\perp} 2 p_{\pi} \\
\text { fact }_{2 s, 2 p}(C)=1.055\end{array}$ & $\begin{array}{c}\sigma \mathrm{fs}_{b} \mathrm{fs}_{b}=0.667 \\
\text { partial dual } \sigma \text { when } \\
\mathrm{s} \nRightarrow \mathrm{p} \\
\text { (all bonding) on both } \\
\text { sides } \\
\pi \text { when } \mathrm{s} \Rightarrow p \text { on both } \\
\text { sides. (0.875 0.875) } \\
\pi \text { bonding is reduced } \\
\text { by coincident } \pi \\
\text { bonding to other } \mathrm{Cs}\end{array}$ & 7.50 \\
\hline
\end{tabular}

a $\mathrm{D}_{0}$ is the molecular bond dissociation energy.

${ }^{\mathrm{b}}$ Bond energies are from (or calculated from data) in W.M. Hayes, Editor in Chief, CRC Handbook of Chemistry and Physics, Section 5, CRC Press (2014).

' Structural data and dipole moment ( $\mu$ ) data are from W.M. Hayes, Editor in Chief, CRC Handbook of Chemistry and Physics, Section 9, CRC Press (2014).

${ }^{d}$ fact is the orbital scale factor.

Table IX. Components of the $\mathrm{C}_{2}$ Calculation at $1.243 \AA$ (Energy in electron volts)

The configuration of $C$ in $C_{2}$ is $1 s^{2} 2 s^{2} 2 p_{x y}^{2}$.

\begin{tabular}{lcl}
\hline Component & Value $\begin{array}{l}\text { Energy }(\mathrm{eV}) \\
\text { Increment }\end{array}$ \\
\hline
\end{tabular}


\begin{tabular}{ll}
\hline Sigma overlap of one pair of orbitals (overlap s_s $\left._{s}\right)$ & 0.7071
\end{tabular}

(There are two pairs of $2 \mathrm{~s}$ bonding orbitals)

Fraction_bonding s_s

fraction_bonding $s_{s_{-} s}=\left(\right.$ overlap $_{s_{-} s} /\left(1+\right.$ overlap $\left._{s_{-}}\right)$

Simultaneous overlap of both pairs of orbitals (overlap s-s/s-s) $\quad 0.2071$

fraction_bonding $s_{-}$fraction_bonding s_s $_{-} /\left(\left(1-\right.\right.$ fraction_bonding $s_{s_{-}}$

fraction_bonding s_s $_{3}$ )

Total overlap of both pairs (overlap)

1.0000 overlap $=2$ overlap $_{s_{-} s}-2$ overlap $_{s-s / s-s}$

Fraction_bonding of both pairs

0.5000

fraction_bonding = (overlap $/(1+$ overlap $)$

Kinetic energy of bond of one sigma orbital pair (2 KE $\mathrm{bond} \mathrm{s-s}) \quad 5.9265$

$K E_{\text {bond s-s }}=$ Fraction_bonding $\left(K_{s l+s r}-K E_{s l}-K E_{s r}\right)$

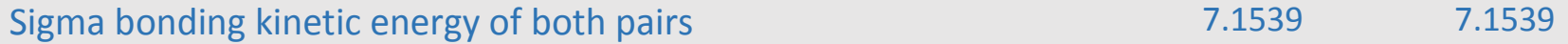

( overlap/(1+overlap))/( (overlap s_s $_{s_{-}} /\left(1+\right.$ overlap $\left.\left._{s_{-}}\right)\right) 2 \mathrm{KE}_{\text {bond s-s }}$

$\begin{array}{lll}\text { Kinetic energy of } 2 \text { pi bonds } 4 \mathrm{KE}_{\text {bond_ } \pi} & 4.2670 & 4.2670\end{array}$

Energy to make sigma pair $2 \mathrm{~s}$ orthogonal to opposite $1 \mathrm{~s}^{2} \quad-6.4001$

$2\left(\mathrm{KE}_{\phi}-\mathrm{KE}_{\phi}\right)$ where $\phi$ is $2 \mathrm{~s}$ made orthogonal, $\phi$ is $2 \mathrm{~s}$

Energy to make $1^{\text {st }}$ pair orthogonal to opposite $1 s^{2}$ when not bonding $\quad-3.2001 \quad-3.2001$ $2\left(\mathrm{KE}_{\phi}-\mathrm{KE}_{\phi}\right)$ (1-fraction_bonding)

Additional Energy to make $2^{\text {nd }}$ pair orthogonal to opposite $1 s^{2} \quad-1.8745 \quad-1.8745$ when bonding and $2^{\text {nd }}$ pair not bonding

$2\left(\mathrm{KE}_{\phi}-\mathrm{KE}_{\phi}\right)$ fraction_bonding (1- fraction_bonding $s_{-}$)

Nuclear-nuclear repulsion energy

$-416.9974 \quad-416.9974$

Nuclear to opposite two 2s sigma orbitals energy

$236.0087 \quad 236.0087$

When not bonding, (1-fraction_bonding), one $2 \mathrm{~s}$ on each atom

becomes an opposing orbital.

Nuclear to opposite 1s orbitals energy

$277.9988 \quad 277.9988$

$\begin{array}{lll}\text { Nuclear to opposite opposing orbitals energy } & 50.4958 & 50.4958\end{array}$

Opposing orbitals occur only when not bonding, (1-fraction_bonding).

The opposing orbital coefficients $\mathrm{fp}_{\mathrm{o}}$ and $\mathrm{fs}_{\mathrm{o}}$ are chosen to make

the orbital orthogonal to the opposite bonding $2 \mathrm{~s}$ orbital.

$\mathrm{fs}_{\text {or }}$ overlap $_{s_{-} s_{-} n}-\mathrm{fp}_{\text {or }}$ overlap $_{s_{-} p z_{-} n}=0.0$

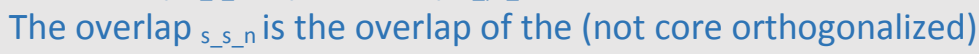

$2 \mathrm{~s}$ atomic orbitals.

Nuclear to opposite $p_{x y}$ orbitals energy

249.6900

249.6900

Electron-electron repulsion energy

$-392.2061$

$-392.2061$

Energy to raise $s$ to $p$

$-4.50$

$-4.50$

2 (1- (overlap/(1+overlap))) $\mathrm{fp}_{\mathrm{o}} \mathrm{fp}_{\mathrm{o}} 6.55+$

2 (1- (overlap/(1+overlap))) $\mathrm{fp}_{\mathrm{b}} \mathrm{fp}_{\mathrm{b}} 7.90+$

4 (overlap/(1+overlap)) $\mathrm{fp}_{\mathrm{b}} \mathrm{fp}_{\mathrm{b}} 7.90$ 
Energy for C atom compression (scale factor 1.035)

$-0.33$

$-0.33$

Total

6.51

Table X. Components of the $\mathrm{CH}_{4}$ Calculation at $1.106 \AA$ (Energy in electron volts)

The configuration of $\mathrm{C}$ in $\mathrm{H}_{4} \mathrm{C}$ is $1 \mathrm{~s}^{2} 2 \mathrm{~s} 2 \mathrm{pz} 2 \mathrm{p}_{x y}{ }^{2}$. $\mathrm{CH}_{4}$ has a tetrahedral structure.

\begin{tabular}{|c|c|c|c|}
\hline Component & Value & $\begin{array}{l}\text { Overlap } \\
\text { change }\end{array}$ & $\begin{array}{l}\text { Energy } \\
\text { (eV) } \\
\text { change }\end{array}$ \\
\hline \multicolumn{4}{|l|}{ Primary $\mathrm{H}-\mathrm{C}$ Bond } \\
\hline $\begin{array}{l}\text { Sigma overlap of primary orbitals (overlap }{ }_{1 s t} \text { ) } \\
\text { overlap } 1 \text { st }=0.5 \text { overlap }_{s-s}+0.5 \text { overlap }_{s-p} \\
f_{b r}=f_{p b r}=0.5\end{array}$ & 0.8814 & 0.8814 & \\
\hline $\begin{array}{l}\text { Fraction_bonding (fraction_bonding } 1 \text { st }) \\
\text { fraction_bonding } 1 \text { st }=\text { overlap }_{1 s t} /\left(1+\text { overlap }_{1 s t}\right)\end{array}$ & 0.4685 & & \\
\hline $\begin{array}{l}\left.\text { Kinetic energy of sigma orbital pair ( } 2 \mathrm{KE}_{\text {bond }}\right) \\
\qquad \mathrm{KE}_{\text {bond }}=\left(1 /\left(1+\text { overlap }_{1 s t}\right)\right)\left(\mathrm{fs}_{\mathrm{br}} \text { overlap }{ }_{s-\mathrm{s}} \mathrm{KE}_{\text {net s-s}}+\mathrm{fp}_{\mathrm{br}} \text { overlap }_{s-\mathrm{p}} K \mathrm{~K}_{\text {net s-pz }}\right)\end{array}$ & 6.5892 & & 6.5892 \\
\hline $\begin{array}{l}\text { Energy to make } \mathrm{H} \text { 1s orthogonal to opposite } \mathrm{C} 1 \mathrm{~s}^{2} \\
\left(\mathrm{KE}_{\phi}-\mathrm{KE}_{\phi}\right) \text { where } \phi \text { is } \mathrm{H} 1 \mathrm{~s} \text { made orthogonal, } \phi \text { is } \mathrm{H} \text { 1s }\end{array}$ & -9.2300 & & \\
\hline $\begin{array}{l}\text { Energy to make } \mathrm{H} 1 \mathrm{~s} \text { orthogonal to opposite } 1 \mathrm{~s}^{2} \text { when not bonding } \\
\left.\qquad \mathrm{KE}_{\text {core_ortho }}=\left(\mathrm{KE}_{\phi}-\mathrm{KE}_{\phi}\right) \text { (1-fraction_bonding } 1 \text { st }\right)\end{array}$ & -4.6150 & & -4.6150 \\
\hline Nuclear-nuclear repulsion energy & -78.1189 & & -78.1189 \\
\hline $\mathrm{C}$ nuclear to $\mathrm{H}$ 1s energy & 82.4697 & & 82.4697 \\
\hline H nuclear to opposite two C 1s orbitals energy & 26.0397 & & 26.0397 \\
\hline H nuclear to opposite 2 s orbital energy & 12.6635 & & 12.6635 \\
\hline $\mathrm{H}$ nuclear to opposite $2 \mathrm{p}_{z}$ orbital energy & 14.9262 & & 14.9262 \\
\hline $\mathrm{H}$ nuclear to opposite two $2 p_{x y}$ orbital energy & 22.8374 & & 22.8374 \\
\hline H electron-C electron repulsions energy & -76.8004 & & -76.8004 \\
\hline Energy to compress/polarize $\mathrm{H}$ & -0.558 & & -0.558 \\
\hline Energy to raise $C 2 s$ to $2 p$ & -1.63 & & -1.63 \\
\hline Energy to compress C orbitals (orbital scale factor $=1.05$ ) & -0.08 & & -0.08 \\
\hline Total primary energy & & & 3.723 \\
\hline Secondary $H-H$ Bond & & & \\
\hline
\end{tabular}




\begin{tabular}{|c|c|c|c|}
\hline Secondary H 1s - H 1s overlap (secondary overlap ${ }_{\mathrm{s}-\mathrm{s}}$ ) & 0.2605 & & \\
\hline $\begin{array}{l}\text { Secondary } \mathrm{H}-\mathrm{H} \text { sigma overlap along primary axis (overlap } 2_{\mathrm{nd}} \text { ) } \\
3 \text { secondary atoms are at } 1.8060 \AA \\
\text { angle from bond axis is } 35.265 \text { degrees } \quad \cos (35.265)=0.8165 \\
\text { overlap } 2_{n d}=0.81650 .8165 \text { overlap }_{s-s}\end{array}$ & 0.1737 & & \\
\hline $\begin{array}{l}\text { Secondary fraction_bonding (fraction_bonding } 2 \text { nd }) \\
\text { fraction_bonding } 2 \text { nd }=\text { overlap } 2 \text { nd }^{\prime}(1+\text { overlap } 2 \text { nd })\end{array}$ & 0.1480 & & \\
\hline $\begin{array}{l}\text { First secondary fraction_bonding increment (fraction_bonding } 2 \text { nd_inc) } \\
\left.\text { fraction_bonding } 2 \text { nd_inc }=0.5 \text { ( } 1 \text { - fraction_bonding }{ }_{1 s t}\right) \text { fraction_bonding } 2 \text { 2nd } \\
\text { Secondary fraction_bonding is } \\
\text { reduced by previous, coincident } 1^{\text {st }} \text { order bonding. } \\
0.5 \text { because secondary spans } 2 \text { primary }\end{array}$ & 0.0393 & & \\
\hline $\begin{array}{l}\text { First secondary overlap increment } \\
\text { first secondary overlap = } \\
\quad \text { fraction_bonding 2nd_inc/(1- fraction_bonding 2nd_inc) }\end{array}$ & 0.0409 & 0.0409 & \\
\hline $\begin{array}{l}\text { Second secondary fraction_bonding reduced } \\
\text { by previous fraction_bonding of both primary and } 1^{\text {st }} \text { secondary. } \\
\text { fraction_bonding previous }=\left(\text { overlap } \text { 1st }^{-}+0.0409\right) /\left(1+\text { overlap } 1_{1 s t}+0.0409\right)\end{array}$ & 0.4798 & & \\
\hline $\begin{array}{l}\text { Second secondary overlap increment } \\
\text { second secondary overlap = } \\
\quad \text { fraction_bonding previous /(1-fraction_bonding previous })\end{array}$ & 0.0400 & 0.0400 & \\
\hline Third secondary overlap increment & 0.0392 & 0.0392 & \\
\hline $\begin{array}{l}\left.\text { Kinetic energy of first } \mathrm{H}-\mathrm{H} \text { bond (KE } E_{\text {bond_2nd }}\right) \\
K E_{\text {bond_2nd }}=\text { fraction_bonding } 2 \text { nd }\left(K E_{s l+s r}-K E_{s l}-K E_{s r}\right)\end{array}$ & 0.3112 & & \\
\hline 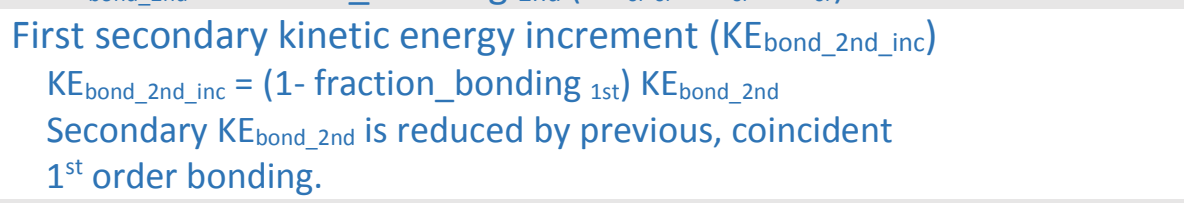 & 0.1654 & & 0.1654 \\
\hline Second secondary kinetic energy increment ( $\left.K E_{\text {bond_2nd_inc }}\right)$ & 0.1586 & & 0.1586 \\
\hline Third secondary kinetic energy increment ( $\mathrm{KE}_{\text {bond_2nd_inc }}$ ) & 0.1524 & & 0.1524 \\
\hline Single $\mathrm{H}$ nuclear-H nuclear repulsion energy & -7.9730 & & \\
\hline $\begin{array}{l}\text { Total nuclear-nuclear repulsion energy } \\
30.5 \text { single nuclear-nuclear repulsion energy } \\
0.5 \text { because spans two primary bonds }\end{array}$ & -11.9595 & & -11.9595 \\
\hline Total H nuclear to opposite H 1s (1.5 single nuclear to opposite) & 24.8811 & & 24.8811 \\
\hline Total H 1s to H 1s electron - electron repulsion (1.5 single ) & -12.7765 & & -12.7765 \\
\hline Total secondary energy & & & 0.6215 \\
\hline Totals & & 1.002 & 4.34 \\
\hline
\end{tabular}




\section{OTHER RESULTS}

The author has obtained results for many other molecules and lithium and beryllium metal. The additional results would require a discussion of sigma resonance, sigma/pi resonance, partial resonance, the impact of resonance on overlap, the calculation of $\mathrm{fs}_{\mathrm{b}} \mathrm{fs}$ for central atoms with bonds that are not identical (e.g. $\mathrm{C}$ in $\mathrm{H}_{3} \mathrm{CCH}_{3}$ ), additional discussion of secondary bonding, and other advanced topics which are beyond the scope of the present paper. The results presented herein are representative.

\section{CONCLUSIONS}

The results presented herein support a model for the chemical bond which recognizes that the two electrons of the bonding pair are not completely identifiable, with respect to their source atom, when their orbitals overlap.

The method for the calculation of the chemical bond, presented here, provides reasonably good results, appears to be general, and is not computationally intensive (A run of six bond lengths takes a few seconds on a desktop PC.). Particularly notable is the discovery that, except for the $\mathrm{H}_{2}$ case, the ratio overlap/ (1+ overlap) is 0.500 at the observed bond length. It is particularly hard to argue that this statistically sensible and computationally uncomplicated result is somehow fortuitous. It is also notable that the method described here is executed in terms understandable to the typical chemist (sigma bonds, pi bonds, hybrid orbitals, resonance, etc.).

${ }^{1}$ C. A. Coulson, Trans. Faraday Soc., 33, 1479(1937).

${ }^{2}$ For an overview of MO and other methods see Ira N. Levine, Quantum Chemistry $7^{\text {th }}$ edition, Pearson (2014) or John P. Lowe, Kirk A. Peterson, Quantum Chemistry $3^{\text {nd }}$ edition, Elsevier Academic Press (2006).

${ }^{3}$ See, for example, Ira N. Levine, Quantum Chemistry $7^{\text {th }}$ edition, pp 252, Pearson (2014).

${ }^{4}$ C.A. Coulson, Valence $2^{\text {nd }}$ edition, pp 91, Oxford University Press (1961).

${ }^{5}$ W.E. Duncanson and C.A. Coulson, Proc.Roy.Soc. (Edinburgh), 62, 37 (1944).

${ }^{6}$ See, for example, W.M. Hayes, Editor-In-Chief, CRC Handbook of Chemistry and Physics $95^{\text {th }}$ Edition, Section 10 pp 10-197, CRC Press (2014).

${ }^{7}$ See, for example, W.M. Hayes, Editor-In-Chief, CRC Handbook of Chemistry and Physics $95^{\text {th }}$ Edition, Section 10 pp 10-147 CRC Press (2014). 